\title{
3 Suppression of Plasmodium MIF-CD74 Signaling Protects Against Severe Malaria
}

4 Alvaro Baeza Garcia ${ }^{1 *}$, Edwin $\mathrm{Siu}^{1}, \mathrm{Xin}^{1}{ }^{1}$, Lin Leng ${ }^{1}$, Blandine Franke-Fayard ${ }^{3}$, Chris J

5 Janse $^{3}$, Shanshan W Howland ${ }^{4}$, Laurent Rénia ${ }^{4}$, Elias Lolis ${ }^{5}$, Richard Bucala ${ }^{1,2 *}$

\section{Affiliations:}

$7{ }^{1}$ Departments of Internal Medicine, ${ }^{2}$ Pharmacology, Yale School of Medicine, and $8 \quad{ }^{2}$ Epidemiology of Microbial Diseases, Yale School of Public Health, New Haven, Connecticut 9 06520, USA. ${ }^{3}$ Department of Parasitology, Leiden University Medical Center, Leiden, Netherlands, 10 Singapore Immunology Network, Agency for Science, Technology and Research (A*STAR), 11 Singapore, Singapore. ${ }^{5}$ Department of Pharmacology, School of Medicine, Yale University, New 12 Haven, CT, 06510, USA.

13 *Correspondence to Richard Bucala, Department of Internal Medicine, Yale University 14 School of Medicine P.O. Box 208031, 300 Cedar St., New Haven, Connecticut 06520-8031, 15 USA. Telephone at (203) 785-2453. Fax at (203) 785-5415. Email at

16 richard.bucala@yale.edu 


\section{Abstract}

Malaria begins when mosquito-borne Plasmodium sporozoites invade hepatocytes and usurp host pathways to support the differentiation and multiplication of erythrocyte-infective merozoite progeny. The deadliest complication of infection, cerebral malaria, accounts for the majority of malarial fatalities. Although our understanding of the cellular and molecular mechanisms underlying the pathology remains incomplete, recent studies support the contribution of systemic and neuroinflammation as the cause of cerebral edema and bloodbrain barrier (BBB) dysfunction. All Plasmodium species encode an orthologue of the innate cytokine, Macrophage Migration Inhibitory Factor (MIF), which functions in mammalian biology to regulate innate responses. Plasmodium MIF (PMIF) similarly signals through the host MIF receptor CD74, leading to an enhanced inflammatory response. We investigated the PMIF-CD74 interaction in the onset of experimental cerebral malaria (ECM) using CD74 deficient ( $C d 74-/-)$ mice, which were found to be protected from ECM. The protection was associated with the inability of brain microvessels from $C d 74^{-/}$hosts to present parasite antigen to sequestered Plasmodium-specific $\mathrm{CD}^{+} \mathrm{T}$ cells. Infection of mice with PMIF-deficient sporozoites (PbAmif-) also protected mice from ECM, highlighting the pivotal role of PMIF in the pre-erythrocytic stage of the infection. A novel pharmacologic PMIF-selective antagonist reduced PMIF/CD74 signaling and fully protected mice from ECM. These findings reveal a conserved mechanism for Plasmodium usurpation of host CD74 signaling and suggest a tractable approach for new pharmacologic intervention. 


\section{Introduction}

Malaria caused by parasites of the genus Plasmodium is the most deadly parasitic disease, causing approximately half a million deaths annually [1]. Plasmodium sporozoites enter the skin through the bite of infected Anopheles mosquitoes and transit through the bloodstream to invade the liver. A single infected hepatocyte produces tens of thousands of erythrocyte-infectious merozoites and initiates the erythrocytic cycle of infection. The subsequent erythrocytic stage of infection produces the disease's clinical manifestations [2], including the most severe complication of P. falciparum infection: cerebral malaria leading to impaired consciousness, seizures, coma, and subsequent mortality [3]. The experimental cerebral malaria (ECM) animal model by infection of susceptible C57BL/6J mice with Plasmodium berghei ANKA $(\mathrm{PbA})$ reproduces many of the neurological signs and pathologic changes of human cerebral malaria [4]. ECM is triggered by parasitized erythrocytes in the cerebral microvasculature leading to the production of inflammatory molecules such as IFN- $\gamma$, granzyme B, and perforin, and is associated with the recruitment and accumulation of effector CD8+ T cells in the CNS $[5,6]$.

Both host and parasite factors contribute to the pre- and erythrocytic stages of infection and severe malaria development. Plasmodium parasites express intricate strategies to evade immune detection and destruction. It is noteworthy that all Plasmodium species analyzed genetically encode an orthologue of the mammalian cytokine macrophage migration inhibitory factor (MIF) [7, 8]. MIF sustains activation responses by promoting innate cell survival, which occurs by signaling through its cognate receptor CD74, leading to sustained ERK1/2 activation and reducing cellular p53 activity $[9,10,11]$. Plasmodium MIF (PMIF) is highly conserved in all known Plasmodium genomes; for instance, only a single amino acid distinguishes murine Plasmodium berghei from human P. falciparum PMIF [7, 8]. Recent evidence has implicated PMIF in the growth and development of liver-stage parasites $[12,13]$, and PMIF binds with high affinity to the host receptor CD74 [14, 15], which has been independently identified as a susceptibility factor for murine Plasmodium infection [16].

In the present study, we show that $P b \mathrm{~A}$ infected $C d 74-/-$ mice are resistant to ECM. Cerebral malaria onset further relies on the contribution of endothelial cell CD74, which is upregulated in the brains of infected mice in the presence of PMIF to promote parasite antigen presentation to brain-sequestered Plasmodium-specific $\mathrm{CD}^{+} \mathrm{T}$ cells. Mice infected with PbAmif- parasites were only resistant to ECM when infected with sporozoites, reinforcing the idea that liver-stage Plasmodium infection is critical for ECM development [17]. In agreement 
104

105

106

107

108

109

110

111

112

113

114

115

116

117

118

119

120

121

122

123

124

125

126

127

128

129

130

131

132

133

134

135

136

with prior studies $[12,13]$, our data also support a central role for PMIF in Plasmodium liver infection. PMIF activates the hepatocellular host MIF receptor CD74 to inhibit the apoptosis of infected hepatocytes, thus promoting Plasmodium development and replication. These findings were recapitulated by pharmacologic inhibition of the PMIF/CD74 interaction with a novel, PMIF-selective small molecule antagonist $[18,19]$ that reduced the survival of infected cells, decreased liver-stage parasite burden, and fully protected mice from acute cerebral malaria.

\section{Results}

\section{CD74 is overexpressed in the brain of $\mathrm{PbA}$ infected mice and contributes to ECM development.}

We recently demonstrated that PMIF exerts its proinflammatory effects by signaling through the host receptor CD74 [20]. To examine the potential role of CD74 in the pathogenesis of ECM, we measured the expression of CD74 in PbA-infected mouse brains during ECM and observed an increase in $C d 74 \mathrm{mRNA}$ expression compared with uninfected mice (Figure 1A). We next challenged WT and $C d 74^{-/}$mice with PbAWT iRBCs and assessed ECM development. While $100 \%$ of the WT mice exhibited neurological symptoms within 7-8 days after infection, $\mathrm{PbA}$-infected $\mathrm{Cd} 74^{-/-}$mice were fully protected from ECM and succumbed to hyperparasitemia only 30 days after infection (Figure 1B, C and S1A). Moreover, we found no significant differences in parasitemia between PbAWT-infected WT or $C d 74^{-/-}$mice during the asymptomatic blood-stage, suggesting that $C d 74$ deficiency does not affect parasite replication in the erythrocyte (Figure S1B). The same results were observed in $C d 74^{-/}$mice infected with PbAmif- parasites (Figures S1C, D, and E). The protection of $C d 74^{-/-}$mice was associated with the downregulation of IFN- $\gamma$, perforin, and granzyme B expression in the brains of $C d 74^{-/-}$versus WT mice but without an appreciable difference in the quantity of brain sequestered parasites (Figure 1D and S1F).

$\mathrm{CD}^{+} \mathrm{T}$ cells are essential for ECM development and contribute directly to human cerebral malaria [4] and ECM pathology [21]. Thus, we investigated if $\mathrm{CD}^{+} \mathrm{T}$ cells from $C d 74^{-/-}$mice have an impaired response to $\mathrm{PbA}$ infection. We measured the amount of brain sequestered $\mathrm{CD}^{+} \mathrm{T}$ cells responding to $\mathrm{PbA}$ by using a $\mathrm{T}$ cell receptor tetramer specific to the PbAGAP50 antigen [22]. Notably, the amount of brain-sequestered PbAGAP50-specific $\mathrm{CD}^{+} \mathrm{T}$ cells was not significantly different between WT and $C d 74^{-/-}$mice (Figure 1E), indicating that $C d 74^{-/-}$mice can mount a $\mathrm{PbA}$ responsive $\mathrm{CD}^{+} \mathrm{T}$ cells response in the brain. Nevertheless, in $C d 74^{-/-}$mice, CD8 $\mathrm{T}$ cell effector functions were strongly suppressed, as 
indicated by the reduced frequency of $P b G A P 50-$ specific $C D 8^{+} \mathrm{T}$ cells expressing the ECMassociated inflammatory molecule Granzyme B (Figure 1F). Our findings suggest that $\mathrm{PbA}$ responsive $\mathrm{CD}^{+} \mathrm{T}$ cells from $\mathrm{Cd} 74^{-/}$mice undergo priming and trafficking to the brain during

$140 \mathrm{PbA}$ blood-stage infection but do not express the inflammatory effector response associated with the development of ECM. We therefore examined if a dysfunctional cytotoxic response

142 in $C d 74$ deficient $\mathrm{CD}^{+} \mathrm{T}$ cells reduced ECM symptoms. For this, we adoptively transferred $143 \mathrm{CD}^{+} \mathrm{T}$ cells from WT or $C d 74^{-/-} \mathrm{PbA}$-infected mice into naïve $\mathrm{Cd} 8^{-{ }^{-}}$or $\mathrm{Cd} 8^{-{ }_{-}} \mathrm{Cd} / 4^{-/-}$recipient mice and infected them with $\mathrm{PbA}$-infected red blood cells (iRBCs) three days later. Recipient $C d 8^{-/}$mice that received $\mathrm{WT}$ or $\mathrm{Cd} 74^{-/} \mathrm{CD} 8^{+} \mathrm{T}$ cells from $\mathrm{PbA}$-infected mice showed signs of ECM and succumbed by day 10 , whereas recipient $C d 8^{-/-} C d 74^{-/}$mice receiving WT or $C d 74^{-}$

/- $\mathrm{CD}^{+} \mathrm{T}$ cells from PbAWT infected mice did not show ECM symptoms and succumbed by 20 days after infection (Figure 1G). Together, these data support the conclusion that $\mathrm{CD}^{+} \mathrm{T}$ cells from $\mathrm{C} d 74^{--}$mice are primed by $\mathrm{PbA}$ antigens but are unable to induce ECM, supporting the role of brain expressed CD74 in the development of ECM pathology.

\section{Cross-presentation of Plasmodium antigen by brain endothelium is CD74 dependent.}

Brain vascular endothelium becomes activated during malaria infection with the ability to process and cross-present Plasmodium antigens [22], thereby contributing to the $\mathrm{T}$ cell effector response and inflammation that underlies ECM [21]. In addition to the role of CD74 as the cognate MIF receptor [10], it functions intracellularly as the MHC class II invariant chain [23] and has been implicated in an MHC class I cross-presentation pathway for cytolytic T lymphocytes (CTL) [24]. We hypothesized that CD74 expressed by activated brain endothelium may cross-present $\mathrm{PbA}$ antigens to prime infiltrating $\mathrm{CD} 8^{+} \mathrm{T}$ cells. Accordingly, we assessed the ability of $P b A$ antigen-pulsed, brain-derived endothelium to activate $\mathrm{T}$ cells by employing the LR-BSL8.4a reporter T cell line that expresses LacZ in response to the PbAGAP50 epitope [6]. $C d 74^{-/}$brain-derived endothelial cells were less able to activate LR-

163 BSL8.4a $\mathrm{T}$ cells in the presence of $\mathrm{PbA}$ antigens when compared to WT brain-derived endothelial cells (Figure 2A). We confirmed these results by isolating brain microvessels from $P b$ A-infected WT and $C d 74^{-/-}$mice at the time of ECM development and incubating them with LR-BSL8.4a reporter T cells for measurement of LacZ expression. Microvessels from PbAinfected WT mice showed a greater ability to cross-present $\mathrm{PbA}$ antigens than microvessels from $C d 74^{-/-}$mice (Figure 2B). We next assessed cross-presentation of $\mathrm{PbA}$ antigens ex vivo by using brain microvessels from $C d 8^{-/-}$or $C d 8^{-\digamma_{-}} C d 74^{-/-}$mice infected with $\mathrm{PbA}$ after adoptive transfer with $\mathrm{CD}^{+} \mathrm{T}$ cells from WT or $C d 74^{-/-}$mice. The microvessels from recipient $\mathrm{Cd} 8^{-/-}$ 
171

172

173

174

175

176

177

178

179

180

181

182

183

184

185

186

187

188

189

190

191

192

193

194

195

196

197

198

199

200

201

202

203

mice receiving WT or $C d 74^{-/-} \mathrm{CD}^{+} \mathrm{T}$ cells from $\mathrm{PbA}$ infected mice had a greater ability to cross-present $\mathrm{PbA}$ antigens (Figure 2C). Together, these results indicate that CD74 expression by brain endothelial cells contributes to cross-presentation of $\mathrm{PbA}$ antigens to $\mathrm{CD}^{+} \mathrm{T}$ cells and to ECM development.

\section{PMIF contributes to the development of ECM by promoting $\mathrm{PbA}$ liver stage development.}

Precedent studies have shown that $\mathrm{PbA}$ parasites genetically deficient in PMIF (PbAmif-) develop normally in their mosquito hosts and during blood-stage infection [14]. To examine the contribution of PMIF to the development of ECM, we infected C57BL6/J mice with wild-type $\mathrm{PbA}(\mathrm{PbAWT})$ or PbAmif- iRBC. There was no difference in ECM manifestations, and all the mice succumbed by day seven after infection (Figure 3A). Recent studies have shown that liver-stage Plasmodium infection is critical for ECM development [17]. We and others recently demonstrated that PMIF is necessary for efficient Plasmodium liver-stage development of the parasite and that its absence impairs blood-stage patency [12, 13]. Accordingly, mice infected with PbAmif- sporozoites did not exhibit ECM signs and survived until day 25 when compared with mice infected with PbAWT sporozoites; the later mice exhibited neurological symptoms followed by mortality 8-9 days after infection (Figure 3B). We measured the expression of CD74 in the brain of infected mice during ECM and observed an increase in $C d 74$ mRNA expression in the brains of PbAWT infected mice when compared with brains of PbAmif- infected mice (Figure 3C). The expression of the inflammatory molecules IFN- $\gamma$, perforin, and granzyme B in the brains of mice infected with PbAWT sporozoites also was higher than in mice infected with PbAmif-sporozoites (Figure 3D).

To evaluate the contribution of the PMIF/CD74 interaction to Plasmodium antigen cross-presentation and ECM development, we infected WT mice with PbAWT or PbAmifsporozoites isolated the brain microvessels at the time of ECM onset, and we incubated them with LR-BSL8.4a reporter T cells. We observed that microvessels from PbAWT infected mice exhibited a greater ability to cross-present $\mathrm{PbA}$ antigens than microvessels from $\mathrm{PbAmif}$ infected mice (Figure 3E). Together, these data confirm the role of PMIF in liver-stage Plasmodium infection and the subsequent promotion of inflammation during blood-stage infection and ECM development. 
PMIF promotes Plasmodium-infected hepatocyte survival and p53 inhibition through host CD74.

Prior studies of Plasmodium-infected liver cells have implicated pro-survival roles for hepatocyte growth factor signaling $[25,26]$ and inhibition of the tumor suppressor p53, which is activated by cellular stress to initiate programmed cell death [27]. Mammalian and parasite MIF molecules promote monocyte survival by increasing p53 phosphorylation at Ser ${ }^{15}$ $[9,11]$. Our results suggest that PMIF regulates $P b$ A liver-stage development and promotes the development of ECM. We observed that intracellular parasite content was reduced in HepG2 cells infected with PbAmif- sporozoites when compared with PbAWT sporozoites

213 (Figure 4A). We used circumsporozoite (CSP) and merozoite surface protein-1 (MSP-1) as 214 indicators of parasite maturation [28]. While CSP was expressed in similar levels (Figure S2A), there was reduced expression of MSP-1 in the HepG2 cells infected with PbAmifparasites, suggesting that PMIF is not necessary for hepatocyte infection but may have a permissive role in pre-erythrocytic parasite development (Fig S2B). To assess the mechanistic role of PMIF in liver-stage parasite development, we examined its effect on the survival of infected liver cells by treating infected HepG2 cells with the nitric oxide (NO) donor sodium nitroprusside (SNP) to induce p53 accumulation and apoptosis. We found that HepG2 cells infected with PbAmif- sporozoites were significantly more susceptible to NO-induced apoptosis than cells cultured with PbAWT parasites, despite a reduced infection level compared with $\mathrm{PbAWT}$ sporozoites (Figure 4B). The protection from apoptosis observed in $\mathrm{PbAWT}$ infected HepG2 cells was associated with decreased phospho-p53 ${ }^{\mathrm{Ser} 15}$ and intracellular p53 content compared with PbAmif- infected cells (Figure 4C). Induction of apoptosis in $\mathrm{PbAmif}$ - versus $\mathrm{PbAWT}$ infected cells also was associated with increased Akt phosphorylation (Figure S2C). We confirmed these in vitro findings by infecting mice with PbAWT or PbAmif-sporozoites. The livers of PbAmif- infected mice showed an $80 \%$ reduction in parasite burden compared with the livers of PbAWT infected mice, and this was associated with an attendant decrease in expression of the host pro-survival gene $\mathrm{Bcl}-2$ and an increase in the expression of the pro-apoptotic gene Bad (Figure S2D).

We next confirmed the direct role of PMIF signaling through the host MIF receptor by studying sporozoite infection in HepG2 cells after knockdown of CD74 (Figure S2E). HepG2 cells treated with shCD74 to reduce CD74 expression had decreased parasite burden compared with treatment with a non-relevant shRNA (shCon) (Figure 4D). As expected, PbAWT infected shCD74-treated cells were more susceptible to apoptosis than infected shCon-treated cells (Figure 4E). Apoptosis induction also was associated with increased cellular $\mathrm{p} 53^{\mathrm{Ser} 15}$ and 
p53 accumulation in the infected HepG2 cells with reduced CD74 expression (Figure 4F). Infection of mice genetically deficient in CD74 $\left(C d 74^{--}\right)$with $P b A W T$ sporozoites revealed a significant reduction in liver burden of Plasmodium parasites when compared to WT $\left(C d 74^{+/+}\right)$ mice (Figure 4G), and this reduction was associated with a delay in blood-stage patency from 2 to 6 days post-infection (Figure S2F). These results support the essential role of CD74 in mediating PMIF action and promoting Plasmodium pre-erythrocytic development leading to blood-stage infection.

Pharmacologic PMIF antagonism reduces $\mathrm{PbA}$ infection and protects against cerebral malaria.

Our experimental results support a central role in malaria infection for host CD74 and its activation by PMIF to promote the survival of infected hepatocytes, leading to inflammatory blood-stage infection and subsequent ECM pathophysiology. Anti-PMIF antibodies have been reported in malaria patients [29] and we assessed the ability of malaria infected sera to interfere with PMIF binding to CD74 using an established ELISA employing the recombinant CD74 ectodomain $[19,30]$. Such sera inhibited PMIF binding to CD74 when compared to sera from uninfected healthy controls (Figure 5A). Moreover, sera from patients with clinically uncomplicated malaria were more effective in reducing PMIF/CD74 interaction than sera from those with complicated malaria (e.g., severe anemia, cerebral malaria [15]), suggesting that a more effective anti-PMIF serologic response may be associated with reduced inflammatory sequelae during infection.

Small molecule MIF inhibitors have been developed and are in clinical evaluation [31, 32]. We recently identified a small molecule PMIF antagonist, termed 26k, that shows a 2500fold greater selectivity for PMIF than for host MIF $\left(K_{i}=40 \mathrm{nM}\right.$ for PMIF versus $\mathrm{Ki}>100 \mu \mathrm{M}$ for MIF) [18] [19] and blocks downstream ERK1/2 MAPK signaling (Figure S3A). We treated $\mathrm{PbA}$ sporozoite infected HepG2 cells with 26k in vitro and measured parasite content by expression of $\mathrm{PbA18s}$ RNA together with sensitivity to apoptosis induction. Parasite burden decreased in the cells treated with 26k compared with vehicle (Figure S3B). Hepatocytes infected with $\mathrm{PbA}$ and treated with 26k also were more susceptible to apoptosis, as evidenced phosphorylation and intracellular accumulation, a known consequence of CD74 blockade (Figure 5C) [9].

To determine the potential in vivo action of $26 \mathrm{k}$, we treated C57BL/6J mice with $26 \mathrm{k}$ before infection with $2 \times 10^{3} \mathrm{PbA}$ sporozoites and then continued treatment once daily for 2 
271

272

273

274

275

276

277

278

279

280

281

282

283

284

285

286

287

288

289

290

291

292

293

294

295

296

297

298

299

300

301

302

303

304

days. We assessed liver-stage infection, blood-stage patency, and the development of ECM and lethality. Treatment with 26k markedly decreased parasite burden in the liver at $48 \mathrm{~h}$ after infection when compared with vehicle controls (Figure 5D and E). Sporozoite infection led to blood-stage patency after 3 days in vehicle-treated mice but not until day 5 in the $26 \mathrm{k}$ treated group (Figure S3C). All vehicle-treated mice developed ECM symptoms (head deviation, ataxia, and paraplegia) 8 days after sporozoite infection, and all mice succumbed to cerebral malaria by days 9-10. By contrast, all mice treated with 26k were spared from cerebral malaria symptoms and did not succumb until after day 20 (Figure 5F, and S3D). We also examined the impact of $26 \mathrm{k}$ on Plasmodium antigen cross-presentation by brain microvascular endothelial cells. Brain microvessels from $P b$ A infected WT mice were isolated at the time of ECM and treated in vitro with 26k (or vehicle) together with LR-BSL8.4a reporter T cells. Microvessels treated with $26 \mathrm{k}$ showed a reduction in $\mathrm{PbA}$ antigen cross-presentation as quantified by LacZ expression (Figure 5G). We also examined if 26k administration in vivo prevented ECM when mice were inoculated directly with iRBCs. We observed only partial protection from ECM in mice treated with 26k in this model (Figure S3E).

Taken together, these results support the conclusion that pharmacologic inhibition of the PMIF/CD74 interaction may be a promising approach to protect from liver infection and, consequently, ECM.

\section{Discussion}

Plasmodium parasites have evolved highly specialized invasion strategies that function to evade immune destruction, sustain infection, and ensure completion of their life cycle. Our study highlights the importance of the pre-erythrocytic phase of infection in the development of the immune response and the subsequent progression of ECM. The present findings also emphasize the importance of investigating Plasmodium genes whose pathologic relevance may be underestimated based on the stage of the infection.

Our precedent studies reported that PMIF promotes inflammatory signaling through the host MIF receptor CD74 [15]. We show herein that PMIF increases the expression of CD74 in the brain of infected mice and serves a previously unforeseen role in the cross-presentation of Plasmodium antigens to promote a CD8+ T cell-mediated, pathologic inflammatory response. Increased IFN $\gamma$ expression also is a feature of ECM pathology [33] and may further contribute to brain endothelial CD74 expression [34]. While dendritic cells are considered the primary antigen-presenting cells responsible for activating CD4 and CD8 T cell responses against Plasmodium [35], endothelial cell activation contributes importantly to blood-brain barrier 
305

306

307

308

309

310

311

312

313

314

315

316

317

318

319

320

321

322

323

324

325

326

327

328

329

330

331

332

333

334

breakdown and neurological disease [6, 22]. Our data further implicate PMIF, which appears to be universally expressed by the Plasmodium genus [30, 31], and its interaction with hepatocyte CD74 as an adaptive mechanism for sporozoites to usurp a host-protective apoptosis pathway to prevent their destruction and enable differentiation and patent infection.

Independent genetic studies indicate that relative increases in liver CD74 expression correlate with enhanced susceptibility to hepatocyte infection by sporozoites [16]. Immunostaining studies suggest that PMIF is expressed on the surface of infective sporozoites and within the parasitophorous vacuole during liver stage development $[12,14]$. The precise localization of PMIF interaction with host CD74 is currently unclear; however, we suggest two possible scenarios: 1) by contact between PMIF on the invading sporozoite and CD74 expressed on the hepatocyte cell surface, or 2) after sporozoite internalization and contact between PMIF in the parasitophorous vacuole and endosomal-expressed CD74 during laterstage Plasmodium development [36]. Either pathway could initiate activation of Akt and cellular pro-survival pathways [27]. It is also notable that PMIF vaccination is associated with a more robust liver resident memory $\mathrm{CD} 8+\mathrm{T}$ cell response, suggesting that the apoptotic destruction of infected hepatocytes promotes the development of protective immunity [13].

We additionally show that the PMIF/CD74 interaction pathway is amenable to pharmacologic targeting. The PMIF selective antagonist 26k [28,29] recapitulates the experimental effects of genetic PMIF or CD74 deficiency, and short term administration of 26k reduced $\mathrm{PbA}$ intrahepatic development and provided complete protection against cerebral malaria. Together with precedent co-crystallization studies supporting the selectivity of $26 \mathrm{k}$ for PMIF versus host MIF, these results provide proof-of-concept for pharmacologic PMIF antagonism as a tractable approach for malaria prophylaxis or liver-stage treatment, and potentially across a range of Plasmodium species and strains [29]. PMIF is highly conserved among Plasmodium species, with only five single nucleotide polymorphisms in PMIF among the 202 sequenced strains of $P$. falciparum present in the PlasmoDB resource $[9,10]$. This high degree of structural conservation may be auspicious for therapeutic targeting, particularly in a genetically complex pathogen prone to resistance development. Additional studies to optimize the absorption, distribution, metabolism, and excretion properties of $26 \mathrm{k}$ will be necessary to advance PMIF selective inhibitors such as $26 \mathrm{~K}$ into clinical utility. 


\section{Materials and Methods}

Mice

338 Female WT or $C d 74^{-/-}$C57BL/6J mice between 6-10 weeks of age were purchased from The 339 Jackson Laboratory and used for the study. $C d 8^{--} C d 74^{-/}$mice were obtained by crossing $C d 8^{-}$ 340 / with $C d 74^{-/-}$mice. Swiss Webster mice were obtained from The Jackson Laboratory. All 341 animals were maintained in a specific pathogen-free facility at Yale Animal Resource Center. 342 All animal procedures followed federal guidelines and were approved by the Yale University

343 Animal Care and Use Committee, approval number 2017-10929.

\section{Parasites and infection}

PbAWT (MR4), PbAmif- (Leiden Malaria Group) [14], or PbAWT-GFP-luciferase (MR4) parasites were cycled between Swiss Webster mice and Anopheles stephensi mosquitoes. For erythrocytic infection, cryopreserved stocks of infected red blood cells (iRBCs) were injected $\left(10^{6} \mathrm{iRBCs} / \mathrm{mouse}\right)$, and blood parasitemia was monitored by Giemsa-stained blood smears and flow cytometry [13]. For the pre-erythrocytic stage infection, salivary gland sporozoites were extracted from infected mosquitoes on day 19 post-blood meal infection. WT or $C d 74^{-/-}$ C57BL/6J mice were infected by i.v. tail injection of $2000 \mathrm{PbAWT}, \mathrm{PbAmif}$ - or PbAWT-GFPluciferase sporozoites, and blood patency was monitored beginning day 3 by blood smear and flow cytometry. Liver parasite burden was monitored at $48 \mathrm{~h}$ after infection using an IVIS imaging system (Caliper) or quantitative PCR [13].

355 For adoptive transfer, splenocytes were isolated six days after infection of WT or $C d 74-/-$ mice infected with $10^{6} \mathrm{PbAWT}$ iRBC, CD8 T cells were purified with anti-CD8 (Ly-2, Miltenyi Biotech) according to the manufacturer's protocol. $1 \times 10^{7}$ cells were transferred, i.v. into recipient C57BL6/J $C d 8^{-{ }_{-}}$or $C d 8^{-/-} C d 74^{-\digamma_{-}}$mice and mice infected three days after with $10^{6}$ PbAWT iRBC.

360 Hepatocyte infection, apoptosis induction, Annexin V assay, and quantification of p53 by western blotting

362 For apoptosis assessment, $1 \times 10^{5} \mathrm{HepG} 2$ cells (ATCC) were seeded in complete EMEM 363 medium (ATCC) (10\% FBS (Atlanta Biologicals), 1\% streptomycin/penicillin (Thermo364 Fisher), and infected with $2 \times 10^{3} \mathrm{PbAWT}$ or PbAmif- sporozoites. $48 \mathrm{~h}$ after infection, cells were treated with $1 \mathrm{mM}$ of SNP (Sodium Nitroprusside, Sigma) for $4 \mathrm{~h}$ or left untreated as a control. For PMIF pharmacologic inhibition, cells were treated with 26k (10 nM, $100 \mathrm{nM})$ or with an equivalent concentration of vehicle ( $0.1 \%$ DMSO) (Sigma) before infection. Cells then 
368

369

370

371

372

373

374

375

376

377

378

379

380

381

382

383

384

385

386

387

388

389

390

391

392

393

394

395

396

397

398

399

400

were detached with Acutase (MP Bio), and cell suspensions split for Western blot or Annexin V analysis. For Annexin V analyses, cells were stained with Pacific Blue-Annexin V and 7AAD (7-aminoactinomycin D) (Biolegend) before running in an LSRII cytometer (BD Biosciences). For quantification of p53 by western blotting, PbAWT-infected HepG2 hepatocytes were detached with Accutase (MP Biolabs) and pelleted. Western blots were performed by lysing cell pellets in RIPA buffer (ThermoFisher) according to standard protocols and using antibodies directed against p53-Ser ${ }^{15}$ (clone 1C12) or total p53 (pAb) (Cell Signaling Technology). For quantification, density signals were normalized to an anti- $\beta$-actin $\mathrm{Ab}$ (LICOR) and developed with anti-mouse or anti-rabbit Abs conjugated with HRP (LI-COR Biosciences). Membranes were visualized using an Odyssey-Fc imaging system (LI-COR Biosciences). Each western blot panel was developed from the same membrane that was reprobed after stripping.

\section{Quantification of liver-stage $P b A W T$ and $P b A m i f-$ infection, and $C d 74$ knockdown}

HepG2 liver cells infected with PbAWT or PbAmif- sporozoites were lysed at $24 \mathrm{~h}$ or $48 \mathrm{~h}$ after infection, cellular proteins transferred to PVDF membranes (Millipore), and analyzed by western blotting using anti-CSP (MRA-100) and anti-MSP-1 (MRA-667) antibodies obtained from MR4 ATCC (Manassas, VA). $\beta$-actin was used as a loading control. For treatment with siRNA, hepatocytes were transfected with 15 pmol of siRNA (Ambion) targeting CD74 mRNA (3 target sequences in exon 2) or siCtrl (scrambled unrelated sequence) as a negative control. siRNA was complexed with Lipofectamine RNAimax reagent (ThermoFisher) and added to the cells for $24 \mathrm{~h}$; cells then were infected with PbAWT sporozoites.

\section{Murine $P b A$ infection and 26k treatment}

C57BL/6J mice received three i.p. injections of 26k (4-(3-methoxy-5-methylphenoxy)-2-(4methoxyphenyl)-6-methylpyridine) [18], synthesized by CheminPharma LLC (Branford, Connecticut), at $80 \mathrm{mg} / \mathrm{kg}$ after dissolution in PEG400 (Sigma-Aldrich) in a sonicating water bath. HP-P-cyclodextrin (Sigma-Aldrich) was added to prepare a $4 \mathrm{mg} / \mathrm{ml}$ solution. Control mice received vehicle alone. Immediately after the first i.p. injection, mice were infected i.v. with $2 \times 10^{3} \mathrm{PbA}$-luc-GFP sporozoites; the second and third injections of $26 \mathrm{k}$ were given $24 \mathrm{~h}$ and $48 \mathrm{~h}$ later, and always after measurement of $\mathrm{PbA}$ liver burden. The $\mathrm{PbA}$ liver burden was quantified $48 \mathrm{~h}$ after infection by luminescence emission after luciferin injection (Perkin Elmer) using an IVIS apparatus (Caliper). Livers were excised $48 \mathrm{~h}$ after infection, the total RNA extracted and purified with Trizol (Life Technologies), and parasites quantified by RTqPCR using primers for $P b 18$ s. 
401

402

403

404

405

406

407

408

409

410

411

412

413

414

415

416

417

418

419

420

421

422

423

424

425

426

427

428

429

430

431

432

\section{Brain microvessel cross-presentation assay}

WT, $C d 74^{-/}, C d 8^{-/}$or $C d 8^{-/} C d 74^{-/}$C57BL/6J mice were infected by intravenous injection of sporozoites or by intraperitoneal injection of $\mathrm{PbA}$ infected red blood cells. Infected mice were sacrificed when the signs of ECM (head deviation, ataxia) were manifested. Control naïve mice were sacrificed contemporaneously with the experimental group. The technique for isolating brain microvessels and quantification of cross-presentation of the parasite-derived GAP50 epitope by LR-BSL8.4a reporter T cells [22] was performed according to the published protocol [21]. Quantification of $\beta$-galactosidase activity by activated LR-BSL8.4a reporter cells was performed by using a luminescence $\beta$-galactosidase assay (ThermoFisher) and the resultant signal quantified with a microplate reader (Tecan).

\section{Isolation of Brain-infiltrating lymphocytes for flow cytometry.}

Naïve or infected WT and C $d 74^{-/-}$C57BL/6J mice were sacrificed and perfused intra-cardially with $20 \mathrm{ml}$ 1x DPBS (' 'Dulbecco's Phosphate Buffer Saline). Brains were minced in RPMI, digested with $10 \mu \mathrm{g} / \mathrm{ml}$ of DNase I (Sigma) and $0.5 \mathrm{mg} / \mathrm{ml}$ for $30 \mathrm{~min}$ at $37^{\circ} \mathrm{C}$, and homogenized with a pestle then filtered with a $70 \mu \mathrm{m}$ cell-strainer (BD Falcon). The suspension then was centrifuged at 200xg for 5min, and the pellet re-suspended in 90\% Percoll (GE Healthcare) and overlaid with a 70\%, 50\% and 30\% Percoll gradient. After centrifugation at $500 x g$ for $10 \mathrm{~min}$, the cell interphase was collected treated with RBC lysis buffer, washed once, and re-suspended in complete RPMI medium (containing 10\% FBS (Atlanta Biologicals) and $1 \%$ penicillin-streptomycin (Thermo Fisher)). $100 \mu \mathrm{l}$ of brain cell suspensions were stimulated with $1 \mu \mathrm{M}$ of peptide (SQLLNAKYL) in the presence of $10 \mu \mathrm{g} / \mathrm{ml}$ Brefeldin A. After $5 \mathrm{~h}$ incubation at $37^{\circ} \mathrm{C}$, the cells were centrifuged and washed once with $100 \mu \mathrm{DPBS}+5 \% \mathrm{FBS}$. The cells then were re-suspended and incubated with FITC-labelled SQLLNAKYL-H- ${ }^{2 b}$ tetramer for $15 \mathrm{~min}$ on ice before staining with anti-CD8-PE Cy7 (clone 53-6.7, Biolegend), anti-CD4-PerCP Cy 5.5 (clone RM4, Biolegend), and anti-CD11a antibodies in the presence of FCR-block for $20 \mathrm{~min}$ on ice. Cells were washed, pelleted, and permeabilized by resuspension in $100 \mu \mathrm{l}$ Fix/Perm buffer on ice for $15 \mathrm{~min}$. Cells then were washed once with $1 \mathrm{x}$ Perm Wash buffer (BD Bioscience) and stained with anti-IFN- $\gamma$-APC-Cy7 (clone XMG1.2, Biolegend) and GrmzB-Pe-Cy7 (clone NGZB,eBioescience) in 1x Perm Wash buffer (BD Bioesciences) for $20 \mathrm{~min}$ on ice. Finally, cells were washed, centrifuged once, and resuspended in $200 \mu \mathrm{l}$ PBS+5\% FBS for flow cytometry. The data were acquired on an LSRII flow cytometer (BD Biosciences) and analyzed using the FlowJo software (version 10). 


\section{Patient Samples and PMIF-CD74 binding assay}

435 Sera from a previously characterized Zambian cohort of $P$. falciparum-infected patients were 436 used in the study [15, 37]. The interaction between PMIF and CD74 was analyzed as previously 437 described [19, 30]. Briefly, 96-well plate were coated with $26 \mathrm{ng} / \mathrm{ml}$ of recombinant CD74 438 ectodomain (aa 114-243) in PBS and incubated overnight at $4^{\circ} \mathrm{C}$. After washing with 439 PBS/0.1\% Tween-20, the plate was blocked with Superblock reagent (Pierce) for 2 hours. 440 Biotinylated recombinant PMIF (5ng/ml) was incubated for $45 \mathrm{~min}$, with human serum (diluted 441 1:1000) from a previously described repository of healthy donors or subjects with 442 uncomplicated or complicated malaria [15]. After washing and incubating with Streptavidin443 HRP (Roche), the peroxidase substrate is 3,3'-5,5'-tetramethylbenzidine (TMB, Roche) was 444 added, and after 20 min incubation, the reaction was stopped with $1 \mathrm{~N}_{2} \mathrm{SO}_{4} / \mathrm{HCl}$. The results 445 were expressed as the percentage of binding in the presence versus the absence of serum.

\section{Statistical analysis}

447 All statistical analysis was performed as described before (15), using Software Prism v.6.0, 448 (GraphPad). Statistical significance was indicated at $p$ values of less than $0.05,0.01$, or 0.001 . 449 All data were expressed as a mean \pm SD of at least two independent experiments. Mouse 450 survival times were analyzed by the Mantel-Cox log-rank test. All other data were first tested 451 for Gaussian distribution of values using a D'Agostino-Pearson normality test. The statistical significance of differences was assessed using the Kruskal-Wallis or Mann-Whitney $U$ test for non-parametric data distribution and ANOVA or Student's $t$-test for parametric data.

\section{Ethics Approval}

All animal procedures followed federal guidelines and were approved by the Yale University Animal Care and Use Committee, approval number 2017-10929. De-identified human sera collected from a prior study were used for in vitro ELISA studies (Yale HIC \#0804003730). 
465

466

467

468

469

470

471

472

473

474

475

476

477

478

479

480

481

482

483

484

485

486

487

488

489

490

491

492

493

494

495

496

497

\section{Figures Legends}

Figure 1. CD74 is overexpressed in the brain of $\mathrm{PbA}$ infected mice and contributes to ECM development. A, $C d 74$ mRNA expression measured by qPCR in the brains of wild type (WT) C57BL6/J mice that were either non-infected (NI WT) or infected with $10^{6} \mathrm{PbA}$ iRBC (INF WT). Results are shown as mean \pm SD from two independent experiments with 6 animals per group and experiment: $\# \mathrm{p}<0.0001$ by Mann-Whitney test. CD74 deficient $\left(C d 74^{-/}\right)$and WT C57BL6/J mice were infected i.p with $10^{6} \mathrm{PbA}$ iRBC and the B, Kaplan-Meier survival plots for WT and $C d 74^{-}$mice following infection with $\mathrm{PbA}$ and $\mathbf{C}$, ECM malaria score were assessed. Data are from two pooled independent experiments with 10 animals per group; $\mathrm{p}<0.0001$ by log-rank (Mantel Cox) test. Bars represent the \pm SD of $\mathrm{n}=10 \mathrm{WT}$ and $\mathrm{n}=10 C d 74^{-}$

'- mice and pooled from three independent experiments. D, Transcriptional expression of IFN $\gamma$, perforin and granzyme B was measured in brain tissue of PbA infected WT and Cd74-/- mice on day 7 after infection by quantitative real-time PCR. Results are expressed as mean \pm SD of $\mathrm{n}=6$ mice per group pooled from two experiments: ${ }^{*} \mathrm{p}=0.0159$ and ${ }^{*} \mathrm{p}=0.0317$ by two-tailed Mann-Whitney test. Brain infiltrating lymphocytes from WT and $C d 74^{-/} \mathrm{PbA}$ infected mice were isolated 7 days after infection, and the number of $\mathbf{E}$, pathogenic tetramer-labeled brain CD8+ $\mathrm{T}$ cells $\left(\mathrm{CD} 8^{+} \mathrm{GAP50Tetrah}\right)$, expressing $\mathbf{F}$, the proinflammatory marker GrzmB $\left(\mathrm{CD}^{+} \mathrm{GAP}\right.$ Tetrahi $\left.{ }^{\text {GrzmB }}{ }^{\text {hi }}\right)$ measured by flow cytometry. Data are shown as mean \pm SD of n=6 WT and n=6 $C d 74^{-/}$mice and pooled from two independent experiments; n.s.=nonsignificant; ${ }^{*} \mathrm{p}=0.0022$ by two-tailed Mann-Whitney test. G, Kaplan-Meier survival plots for C57BL6/J mice $\mathrm{Cd} 8^{-/}$and $\mathrm{Cd} 8^{-/} \mathrm{Cd} 74^{-/}$receiving $\mathrm{CD}^{+} \mathrm{T}$ cells isolated from $\mathrm{PbA}$ infected WT or $C d 74^{-/}$and infected with i.p with $10^{6} \mathrm{PbAWT}$ iRBC. Data are form three pooled independent experiments with 6 animals per group; $\mathrm{p}<0.0001$ by log-rank (Mantel Cox) test.

Figure 2. Cross-presentation of Plasmodium antigen by brain endothelium is $\mathrm{Cd74}$ dependent. Cross-presentation of $\mathrm{PbAGAP}_{50}$ by brain endothelial cells. $\mathbf{A}, \mathrm{BEC}$ isolated from WT and $C d 74^{-/-}$mice were stimulated with $10 \mathrm{ng} / \mathrm{ml}$ IFN $\gamma$ for $24 \mathrm{~h}$, and then incubated for additional 24h with $\mathrm{PbA}$ mature stage iRBCS before co-culture with LR-BSL8.4a reporter cells overnight prior to $\beta$-galactosidase activity assessment. Data are shown as mean \pm SD of three independent biological replicates performed in triplicate; $\# \mathrm{p}<0.0001$ by Mann-Whitney test. $\mathbf{B}$, Brain microvessel cross-presentation of $P_{b A G A P}$ from naïve and $P b A$ infected WT and $\mathrm{C} d 74^{-/}$mice. Mice were infected with $10^{6} \mathrm{PbA}, \mathrm{iRBC}$ and brain microvessels were isolated when WT-infected mice exhibited neurological signs at 7 days after infection and co-incubated with LR-BSL8.4a reporter cells for $24 \mathrm{~h}$ and then assessed for $\beta$-galactosidase activity. Data 
498

499

500

501

502

503

504

505

506

507

508

509

510

511

512

513

514

515

516

517

518

519

520

521

522

523

524

525

526

527

528

529

530

are shown as mean \pm SD of $n=6$ mice per group and pooled from two independent biological replicates; ** $\mathrm{p}=0.0021$ by Mann-Whitney test. C, Brain microvessel cross-presentation of $\mathrm{PbAGAP} 50$ from $\mathrm{Cd} 8^{-/}$and $C d 8^{--} \mathrm{Cd} d 4^{-/-}$receiving $\mathrm{CD} 8^{+}$T cells isolated from $\mathrm{PbA}$ infected WT or $C d 74^{-/}$mice three days before the infection with $10^{6} \mathrm{PbAWT}$ iRBC. Brain microvessels were isolated when the first infected mice exhibited neurological signs at 7 days after infection and co-incubated with LR-BSL8.4a reporter cells for $24 \mathrm{~h}$ and then assessed for $\beta$-galactosidase activity. Data are shown as mean $\pm S D$ of $n=5$ mice per group and pooled from two independent biological replicates; $\# \mathrm{p}=0.0017$ and $* * \mathrm{p}<0.0001$ by Kruskal-Wallis test.

Figure 3. PMIF contributes to the development of ECM. A, Kaplan-Meier survival plots for C57BL6/J mice infected with i.p with $10^{6} \mathrm{PbAWT}$ or PbAmif- iRBC. Data are form two pooled independent experiments with a total of 6 animals per group. n.s: non-significant by log-rank (Mantel Cox) test. B, Kaplan-Meier survival plots for C57BL6/J mice infected with $2 \times 10^{3} \mathrm{PbAWT}$ or PbAmif-sporozoites. Data are from three pooled independent experiments with a total of 6 animals per group; $p<0.0001$ by log-rank (Mantel Cox) test. WT C57BL6/J mice were infected i.v with $2 \times 10^{3} \mathrm{PbAWT}$ or PbAmif- sporozoites. C, CD74 transcript expression in the brain of infected mice was measured by q-PCR at day 8 after infection. Results are expressed as mean $\pm \mathrm{SD}$ of $\mathrm{n}=6$ mice per group pooled from two experiments; ** $\mathrm{p}=0.0022$ by Mann-Whitney test. D, Transcriptional expression of IFN $\gamma$, Perforin and Granzyme B was measured in brain tissue of PbAWT or PbAmif- infected WT mice on day 8 after infection by quantitative real-time PCR. Results are expressed as mean \pm SD of $n=6$ mice per group pooled from two experiments; ${ }^{*} \mathrm{p}=0.0022$ for Perforin and IFN $\gamma$ and ${ }^{* *} \mathrm{p}=0.0317$ for Granzyme B, by two-tailed Mann-Whitney test. E, Brain microvessel cross-presentation of PbAGAP50 from naïve (NI) and PbAWT or PbAmif infected WT mice. Mice were infected with $\mathrm{PbAWT}$ or PbAmif- sporozoites and brain microvessels were isolated when PbAWTinfected mice exhibited neurological signs at 7 days after infection. Microvessels then were coincubated with LR-BSL8.4a reporter cells for $24 \mathrm{~h}$ and then assessed for $\beta$-galactosidase activity. Data are shown as mean $\pm S D$ of $n=6$ mice per group and pooled from two independent biological replicates; ${ }^{* *} \mathrm{p}=0.0021$ by Mann-Whitney test.

Figure 4. PMIF promotes Plasmodium-infected hepatocyte survival and p53 inhibition through host CD74. $1 \times 10^{5}$ HepG2 cells were infected with $2 \times 10^{3}$ PbAWT or PbAmifsporozoites. A, Parasite load was measured by quantitative PCR of PbA $18 \mathrm{~S}$ rRNA relative to host GAPDH $48 \mathrm{~h}$ after infection. Data are from three independent experiments performed in duplicate. Bars represent the mean $\pm \mathrm{SD} ;{ }^{*} \mathrm{p}=0.0286$ by Mann-Whitney test. $1 \times 10^{5} \mathrm{PbAWT}$ or 
531

532

533

534

535

536

537

538

539

540

541

542

543

544

545

546

547

548

549

550

551

552

553

554

555

556

557

558

559

560

561

562

563

564

PbAmif- infected HepG2 cells, were cultured for $48 \mathrm{~h}$ and treated with $1 \mathrm{mM}$ of the NO donor sodium nitroprusside (SNP) for $4 \mathrm{~h}$ to induce apoptosis. B, Percentage of apoptotic cells measured by AnnexinV and 7AAD (7-amino-actinomycin D) staining. Data are from three independent experiments performed in duplicate. Bars represent the mean $\pm \mathrm{SD} ;{ }^{*} \mathrm{p}=0.0133$; ** $\mathrm{p}=0.0011 ;{ }^{\Psi} \mathrm{p}<0.0001$; by Kruskal-Wallis test. C, Lysates of the same HepG2 cells in C were assessed for total $\mathrm{p} 53$ and $\mathrm{p} 53^{\mathrm{Ser} 15}$ by Western blotting. NI: non-infected. Numerals represent the mean densitometric scanning ratios. Data are representative of two independent replicates experiments for the western blot analysis. 1x10 $10^{5} \mathrm{HepG} 2$ cells were treated with 10 nM of shRNA directed at CD74 (shCD74) or a control shRNA (shCon), and infected $24 \mathrm{~h}$ later with $2 \times 10^{3}$ PbAWT sporozoites. D, Parasite load was measured by quantitative PCR of PbA 18S rRNA relative to host GAPDH. Data are from three independent experiments performed in duplicate. Bars represent the mean $\pm \mathrm{SD} ; * * \mathrm{p}=0.002$ by Mann-Whitney test. $1 \times 10^{5}$ shCon or shCd74 treated HepG 2 cells, were infected with $2 \times 10^{3}$ PbAWT sporozoites and cultured for $48 \mathrm{~h}$. shRNA cells were then treated with $1 \mathrm{mM}$ of the NO donor SNP for $4 \mathrm{~h}$ to induce apoptosis E, Percentage of apoptotic (measured by AnnexinV and 7AAD staining) PbAWT infected HepG2 cells treated with shCon or shCD74. Data are from three independent experiments performed in duplicate. Bars represent the mean $\pm \mathrm{SD} ; * * \mathrm{p}=0.0095$ and n.s. $=$ nonsignificant; by Kruskal-Wallis test. F, Lysates of the same hepatocytes as in E were assessed for total $\mathrm{p} 53$ and $\mathrm{p} 53^{\mathrm{Ser} 15}$ by Western blotting with $\beta$-actin as loading control. NI: non-infected, INF: $P b A W T$ infected. Numerals represent the mean densitometric scanning ratios. Data are representative of two independent replicate experiments for the western blot analysis. G, Wild type (WT) or $C d 74^{-/}$C57BL/6J mice were infected i.v. with $2 \times 10^{3} \mathrm{PbA}$-luciferase sporozoites and liver $\mathrm{PbA}$-luc load quantified by luminescence at $48 \mathrm{~h}$ after infection. Bars represent the mean $\pm \mathrm{SD} ; * * \mathrm{p}=0.0022$; by Mann-Whitney test.

\section{Figure 5. Inhibition of PMIF/CD74 axis is associated with protection from severe malaria.}

A. Effect of human serum on PMIF binding to the immobilized human CD74 ectodomain (aa 134-232). Measured values are relative to control without serum for each condition ( $n=6$ healthy uninfected controls, $n=6$ uncomplicated malaria, $n=6$ complicated malaria. Mean $\pm S D$; \#p<0.0001 by 1-way ANOVA. B, Percentage of apoptotic PbAWT infected HepG2 cells measured by AnnexinV and 7AAD staining after 26k or vehicle treatment. 1x10 $10^{5}$ PAWT infected hepatocytes treated with $26 \mathrm{~K}(100 \mathrm{nM})$ or vehicle were cultured for $48 \mathrm{~h}$ followed by the addition of the NO donor SNP $(1 \mathrm{mM})$ for $4 \mathrm{~h}$ to induce apoptosis. Data are from three independent experiments performed in duplicate. Bars represent the mean $\pm \mathrm{SD} ;{ }^{*} \mathrm{p}=0.0011$; 
565

566

567

568

569

570

571

572

573

574

575

576

577

578

579

580

581

582

583

584

585

586

587

588

589

590

591

592

593

594

595

596

597

by two-tailed Mann-Whitney test. C, PbAWT infected HepG2 cells were lysed and assessed for total $\mathrm{p} 53$ and $\mathrm{p} 53^{\mathrm{Ser} 15}$ by Western blotting with $\beta$-actin as loading control. Numerals represent the mean densitometric scanning ratios. Data are representative of two independent replicate experiments for the western blot analysis. NI: non-infected, INF: $P b A$ infected. C57BL/6J mice were treated with vehicle or $26 \mathrm{k}(80 \mathrm{mg} / \mathrm{kg}$, ip) before $(0 \mathrm{~h}), 24 \mathrm{~h}$, and $48 \mathrm{~h}$ after i.v. infection with $2 \times 10^{3} \mathrm{PbA}$-luciferase sporozoites. D, Liver $\mathrm{PbA}$-luc burden was quantified by luminescence and $\mathbf{E}$, by qPCR of liver $\mathrm{PbA} 18 \mathrm{~S}$ rRNA relative to host GAPDH $48 \mathrm{~h}$ after infection. Bars represent the mean $\pm \mathrm{SD} ; * * \mathrm{p}=0.0043(\mathbf{D}),{ }^{*} \mathrm{p}=0.0079(\mathbf{E})$; by MannWhitney test. F, Kaplan-Meier survival plots for vehicle and 26k treated mice following infection with $\mathrm{PbA}$-luc sporozoites. Data are from two pooled independent experiments with 6 animals per group; ${ }^{* *} \mathrm{p}=0.0023$ by log-rank (Mantel Cox) test. G, Brain microvessel crosspresentation of $\mathrm{PbAGAP50}$ from vehicle and $26 \mathrm{k}$ treated mice following infection with $\mathrm{PbA}$ luc sporozoites. Brains microvessels were isolated when vehicle-treated, infected mice exhibited neurological signs at 9 days after infection and co-incubated with LR-BSL8.4a reporter cells for $24 \mathrm{~h}$ and then assessed for $\beta$-galactosidase activity. Data are shown as mean $\pm \mathrm{SD}$ of $\mathrm{n}=6$ mice per group and pooled from two independent biological replicates; ** $\mathrm{p}=0.0022$ by two-tailed Mann-Whitney test.

Figure S1. CD74 is necessary for the development of ECM. A, Peripheral blood parasitemia for CD74 deficient $\left(C d 74^{-/}\right)$and WT C57BL6/J mice infected i.p with $10^{6} \mathrm{PbA}$ iRBC. B, Peripheral blood parasitemia during the 6 first days of infection. Data are shown as mean \pm SD of $\mathrm{n}=10 \mathrm{WT}$ and $\mathrm{n}=10 \mathrm{Cd} 74^{-/-}$mice and pooled from three independent experiments. Wild type (WT) and $C d 74^{-/}$C57BL6/J mice were infected i.p with $10^{6}$ PbAmif iRBC C, Kaplan-Meier survival plots for WT and $C d 74^{--}$mice following infection with PbAmif. Data are from two pooled independent experiments with 10 animals per group; $\mathrm{p}<0.0001$ by log-rank (Mantel Cox) test $\mathbf{D}$, peripheral blood parasitemia. E, ECM malaria score was assessed as described before. Data are shown as mean $\pm \mathrm{SD}$ of $\mathrm{n}=7 \mathrm{WT}$ and $\mathrm{n}=10 \mathrm{Cd} \mathrm{4}^{-/-}$mice and pooled from 2 independent experiments. F, PbA18s transcript expression in the brain of infected WT and $C d 74^{-/}$measured by quantitative real-time PCR 7 days after infection was measured in brains tissue of $\mathrm{PbA}$ infected WT and $C d 74^{-/}$mice on day 7 after infection by quantitative real-time PCR. Results are expressed as mean \pm SD of $n=6$ mice per group pooled from two experiments; n.s.: non-significant by Mann-Withney test.

Figure S2. PMIF influences $P b A$ liver-stage development and promotes survival of Plasmodium-infected hepatocytes by inhibiting p53 activity. $1 \times 10^{5}$ HepG2 cells were 
598

infected with $2 \times 10^{3} \mathrm{PbAWT}$ or PbAmif- sporozoites. Hepatocellular content of A, CSP and B, MSP-1 at $24 \mathrm{~h}$ and $48 \mathrm{~h}$ after infection with $2 \times 10^{3} \mathrm{PbAWT}$ or PbAmif- sporozoites assessed by western blot relative to $\beta$-actin as loading control. Hepatocellular content of MSP-1 at $48 \mathrm{~h}$ after infection with 2x103 $\mathrm{PbAWT}$ or PbAmif- sporozoites was also assessed by western blot relative to PbAHSP70 as loading control. Cultured hepatocytes $\left(1 \times 10^{5}\right.$ HepG2 cells/well) infected with $2 \times 10^{3} \mathrm{PbAWT}$ or PbAmif-sporozoites followed by the addition of $1 \mathrm{mM} \mathrm{SNP}$ at $4 \mathrm{~h}$ and $48 \mathrm{~h}$ after infection. C, Lysates were assessed for total Akt and $\mathrm{pAkt}^{\mathrm{Ser} 473}$ by Western blotting with $\beta$-actin as loading control. Numerals represent the densitometric scanning ratios. D, Transcriptional expression of IFN $\gamma$, Perforin and Granzyme B was measured in brain tissue of PbAWT or PbAmif- infected WT mice on day 8 after infection by quantitative real-time PCR. Results are expressed as mean \pm SD of $n=6$ mice per group pooled from two experiments; ${ }^{* *} \mathrm{p}=0.0022$ for Perforin and IFN $\gamma$ and ${ }^{* *} \mathrm{p}=0.0317$ for Granzyme B, by two-tailed MannWhitney test. $1 \times 10^{5}$ HepG2 cells were treated with $10 \mathrm{nM}$ of shRNA directed at CD74 (shCD74) or a control shRNA (shCon), and infected $24 \mathrm{~h}$ later with $2 \times 10^{3} \mathrm{PbAWT}$ sporozoites. E, $C d 74$ mRNA expression measured by qPCR in HepG2 after $48 \mathrm{~h}$ treatment. Data are from three independent experiments performed in duplicate. Bars represent the mean $\pm \mathrm{SD} ; * * \mathrm{p}=$ 0.002 by Mann-Whitney test. Wild type (WT) or $C d 74^{-/}$C57BL/6J mice were infected i.v. with $2 \times 10^{3} \mathrm{PbA}$-luciferase sporozoites and liver $\mathrm{PbA}$-luc load quantified by luminescence at $48 \mathrm{~h}$ after infection. Bars represent the mean $\pm \mathrm{SD} ; * * \mathrm{p}=0.0022$; by Mann-Whitney test. F, Kaplan-Meier plots showing the percentage of WT (•) and Cd74-/- (०) C57BL/6J mice with blood-stage patency following i.v. infection with $2 \times 10^{3} \mathrm{PbA}$-luc sporozoites. Patency was determined by microscopic enumeration of thin blood smears. Data are from two independent experiments, with 3-4 animals per group; $\mathrm{p}<0.0001$ by Log-rank (Mantel Cox) test.

\section{Figure S3. The small molecule PMIF antagonist 26k reduces PMIF/CD74 signal}

transduction and protects from ECM. A. BMDM were treated with or without recombinant PMIF pre-incubated with vehicle control (DMSO) or small molecule 26k (10,50 or $100 \mathrm{nM})$ for $2 \mathrm{~h}$. Cells were lysed and the lysates assessed for total ERK and $\mathrm{pERK}^{\mathrm{Thr202/Tyr204}}$ by western blotting. Numerals represent the densitometric scanning ratios. HepG2 cells ( $1 \times 10^{5}$ cells/well) were infected with $2 \times 10^{3} \mathrm{PbAWT}$ sporozoites and treated with $26 \mathrm{k}$ or vehicle. $\mathbf{B}$, Hepatocellular parasite load was measured by quantitative PCR of PbA $18 \mathrm{~S}$ rRNA relative to host GAPDH $48 \mathrm{~h}$ after treatment with $26 \mathrm{k}(0.5 \mathrm{nM}$ to $50 \mu \mathrm{M})$ or vehicle. Data are from three independent experiments performed in duplicate. Bars represent the mean $\pm \mathrm{SD} ;{ }^{*} \mathrm{p}=0.0336$, $* * \mathrm{p}=0.0021, \Psi \mathrm{p}=0.0008, \# \mathrm{p}<0.0001$ by Kruskal-Wallis test. $\mathrm{C} 57 \mathrm{BL} / 6 \mathrm{~J}$ mice were treated with vehicle or $26 \mathrm{k}\left(80 \mathrm{mg} / \mathrm{kg}\right.$, ip) before $(0 \mathrm{~h}), 24 \mathrm{~h}$, and $48 \mathrm{~h}$ after i.v. infection with $2 \times 10^{3}$ 
bioRxiv preprint doi: https://doi.org/10.1101/2021.02.14.430970; this version posted April 7, 2021. The copyright holder for this preprint (which was not certified by peer review) is the author/funder, who has granted bioRxiv a license to display the preprint in perpetuity. It is made available under aCC-BY 4.0 International license.

632 PbA-luciferase sporozoites. C. Kaplan-Meier plots showing the percentage of vehicle (o) and $63326 \mathrm{k}(\bullet)$ treated mice with blood-stage patency (determined by microscopic enumeration of thin 634 blood smears) following i.v. infection with $2 \times 10^{3} \mathrm{PbA}-$ luc sporozoites and $\mathbf{D}$, ECM malaria 635 score. Data are from two pooled independent experiments, with 6 animals per group $\mathrm{p}<0.0001$ 636 by Log-rank (Mantel Cox) test. C57BL/6J mice were treated with vehicle or $26 \mathrm{k}(80 \mathrm{mg} / \mathrm{kg}$, 637 ip) before $(0 \mathrm{~h})$ and then every two days after i.p infection with $10^{6} \mathrm{PbAWT}$ iRBCs. E, Kaplan638 Meier survival plots for vehicle (o) and 26k (•) treated mice following infection with $\mathrm{PbA}$ 639 iRBC. Data are from two pooled independent experiments with 8 total animals per group; $640 \quad \mathrm{p}=0.0137$ by log-rank (Mantel Cox) test.

641

642

643

644

645

646

647

648

649

650

651

652

653

654

655

656

657

658

659

660

661

662

663

664

665

666

667

668

669

670

671

672

673

674

675

\section{References}

1. WHO. World malaria report 2019. 2019.

2. Langhorne J, Ndungu FM, Sponaas A-M, Marsh K. Immunity to malaria: more questions than answers. Nature Immunology. 2008;9:725. doi: 10.1038/ni.f.205.

3. Milner DA, Whitten RO, Kamiza S, Carr R, Liomba G, Dzamalala C, et al. The systemic pathology of cerebral malaria in African children. Frontiers in Cellular and Infection Microbiology. 2014;4(104). doi: 10.3389/fcimb.2014.00104.

4. Riggle BA, Manglani M, Maric D, Johnson KR, Lee M-H, Neto OLA, et al. CD8+ T cells target cerebrovasculature in children with cerebral malaria. The Journal of Clinical Investigation. 2020;130(3):1128-38. doi: 10.1172/JCI133474.

5. Shaw TN, Stewart-Hutchinson PJ, Strangward P, Dandamudi DB, Coles JA, VillegasMendez A, et al. Perivascular Arrest of CD8+ T Cells Is a Signature of Experimental Cerebral Malaria. PLOS Pathogens. 2015;11(11):e1005210. doi: 10.1371/journal.ppat.1005210.

6. Howland SW, Poh CM, Rénia L. Activated Brain Endothelial Cells Cross-Present Malaria Antigen. PLOS Pathogens. 2015;11(6):e1004963. doi: 10.1371/journal.ppat.1004963. 7. Aurrecoechea C, Brestelli J, Brunk BP, Dommer J, Fischer S, Gajria B, et al. PlasmoDB: a functional genomic database for malaria parasites. Nucleic Acids Research. 2008;37(suppl_1):D539-D43. doi: 10.1093/nar/gkn814.

8. Aurrecoechea C, Barreto A, Basenko EY, Brestelli J, Brunk BP, Cade S, et al. EuPathDB: the eukaryotic pathogen genomics database resource. Nucleic Acids Research. 2016;45(D1):D581-D91. doi: 10.1093/nar/gkw1105.

9. Mitchell RA, Liao H, Chesney J, Fingerle-Rowson G, Baugh J, David J, et al. Macrophage migration inhibitory factor (MIF) sustains macrophage proinflammatory function by inhibiting p53: Regulatory role in the innate immune response. Proceedings of the National Academy of Sciences. 2002;99(1):345-50. doi: 10.1073/pnas.012511599.

10. Leng L, Metz CN, Fang Y, Xu J, Donnelly S, Baugh J, et al. MIF Signal Transduction Initiated by Binding to CD74. The Journal of Experimental Medicine. 2003;197(11):1467-76. doi: 10.1084/jem.20030286.

11. Kamir D, Zierow S, Leng L, Cho Y, Diaz Y, Griffith J, et al. A <em>Leishmania</em> Ortholog of Macrophage Migration Inhibitory Factor Modulates Host Macrophage Responses. The Journal of Immunology. 2008;180(12):8250-61. doi: 10.4049/jimmunol.180.12.8250. 12. Miller JL, Harupa A, Kappe SHI, Mikolajczak SA. Plasmodium yoelii Macrophage Migration Inhibitory Factor Is Necessary for Efficient Liver-Stage Development. Infection and Immunity. 2012;80(4):1399-407. doi: 10.1128/iai.05861-11. 
bioRxiv preprint doi: https://doi.org/10.1101/2021.02.14.430970; this version posted April 7, 2021. The copyright holder for this preprint (which was not certified by peer review) is the author/funder, who has granted bioRxiv a license to display the preprint in perpetuity. It is made available under aCC-BY 4.0 International license.

13. Baeza Garcia A, Siu E, Sun T, Exler V, Brito L, Hekele A, et al. Neutralization of the Plasmodium-encoded MIF ortholog confers protective immunity against malaria infection. Nature Communications. 2018;9(1):2714. doi: 10.1038/s41467-018-05041-7.

14. Augustijn KD, Kleemann R, Thompson J, Kooistra T, Crawford CE, Reece SE, et al. Functional Characterization of the Plasmodium falciparum and P. berghei Homologues of Macrophage Migration Inhibitory Factor. Infection and Immunity. 2007;75(3):1116-28. doi: 10.1128/iai.00902-06.

15. Sun T, Holowka T, Song Y, Zierow S, Leng L, Chen Y, et al. A Plasmodium-encoded cytokine suppresses T-cell immunity during malaria. Proceedings of the National Academy of Sciences. 2012;109(31):E2117-E26. doi: 10.1073/pnas.1206573109.

16. Kaushansky A, Austin LS, Mikolajczak SA, Lo FY, Miller JL, Douglass AN, et al. Susceptibility to Plasmodium yoelii Preerythrocytic Infection in BALB/c Substrains Is Determined at the Point of Hepatocyte Invasion. Infection and Immunity. 2015;83(1):39-47. doi: 10.1128/iai.02230-14.

17. Sato Y, Ries S, Stenzel W, Fillatreau S, Matuschewski K. The Liver-Stage Plasmodium Infection Is a Critical Checkpoint for Development of Experimental Cerebral Malaria. Frontiers in Immunology. 2019;10(2554). doi: 10.3389/fimmu.2019.02554.

18. Dahlgren MK, Garcia AB, Hare AA, Tirado-Rives J, Leng L, Bucala R, et al. Virtual Screening and Optimization Yield Low-Nanomolar Inhibitors of the Tautomerase Activity of Plasmodium falciparum Macrophage Migration Inhibitory Factor. Journal of Medicinal Chemistry. 2012;55(22):10148-59. doi: 10.1021/jm301269s.

19. Pantouris G, Rajasekaran D, Garcia AB, Ruiz VG, Leng L, Jorgensen WL, et al. Crystallographic and Receptor Binding Characterization of Plasmodium falciparum Macrophage Migration Inhibitory Factor Complexed to Two Potent Inhibitors. Journal of Medicinal Chemistry. 2014;57(20):8652-6. doi: 10.1021/jm501168q.

20. Sun T, Holowka T, Song Y, Zierow S, Leng L, Chen Y, et al. A $<$ em>Plasmodium</em>-encoded cytokine suppresses T-cell immunity during malaria. Proceedings of the National Academy of Sciences. 2012;109(31):E2117-E26. doi: 10.1073/pnas.1206573109.

21. Howland SW, Claser C, Poh CM, Gun SY, Rénia L. Pathogenic CD8+ T cells in experimental cerebral malaria. Seminars in Immunopathology. 2015;37(3):221-31. doi: 10.1007/s00281-015-0476-6.

22. Howland SW, Poh CM, Gun SY, Claser C, Malleret B, Shastri N, et al. Brain microvessel cross-presentation is a hallmark of experimental cerebral malaria. EMBO Molecular Medicine. 2013;5(7):984-99. doi: 10.1002/emmm.201202273.

23. Cresswell P. Assembly, Transport, and Function of MHC Class II Molecules. Annual Review of Immunology. 1994;12(1):259-91. doi: 10.1146/annurev.iy.12.040194.001355. PubMed PMID: 8011283.

24. Basha G, Omilusik K, Chavez-Steenbock A, Reinicke AT, Lack N, Choi KB, et al. A CD74-dependent MHC class I endolysosomal cross-presentation pathway. Nature Immunology. 2012;13:237. doi: 10.1038/ni.2225

https://www.nature.com/articles/ni.2225\#supplementary-information.

25. van de Sand C, Horstmann S, Schmidt A, Sturm A, Bolte S, Krueger A, et al. The liver stage of Plasmodium berghei inhibits host cell apoptosis. Molecular Microbiology. 2005;58(3):731-42. doi: 10.1111/j.1365-2958.2005.04888.x.

26. Leirião P, Albuquerque SS, Corso S, Van Gemert G-J, Sauerwein RW, Rodriguez A, et al. HGF/MET signalling protects Plasmodium-infected host cells from apoptosis. Cellular Microbiology. 2005;7(4):603-9. doi: 10.1111/j.1462-5822.2004.00490.x. 
bioRxiv preprint doi: https://doi.org/10.1101/2021.02.14.430970; this version posted April 7, 2021. The copyright holder for this preprint (which was not certified by peer review) is the author/funder, who has granted bioRxiv a license to display the preprint in perpetuity. It is made available under aCC-BY 4.0 International license.

27. Kaushansky A, Ye Albert S, Austin Laura S, Mikolajczak Sebastian A, Vaughan Ashley M, Camargo N, et al. Suppression of Host p53 Is Critical for Plasmodium Liver-Stage Infection. Cell Reports. 2013;3(3):630-7. doi: http://doi.org/10.1016/j.celrep.2013.02.010. 28. Prudêncio M, Mota MM, Mendes AM. A toolbox to study liver stage malaria. Trends in Parasitology. 2011;27(12):565-74. doi: 10.1016/j.pt.2011.09.004.

29. Han C, Lin Y, Shan G, Zhang Z, Sun X, Wang Z, et al. Plasma concentration of malaria parasite-derived macrophage migration inhibitory factor in uncomplicated malaria patients correlates with parasitemia and disease severity. Clin Vaccine Immunol. 2010;17(10):1524-32. Epub 08/11. doi: 10.1128/CVI.00149-10. PubMed PMID: 20702656.

30. Cournia Z, Leng L, Gandavadi S, Du X, Bucala R, Jorgensen WL. Discovery of human macrophage migration inhibitory factor (MIF)-CD74 antagonists via virtual screening. Journal of medicinal chemistry. 2009;52(2):416-24. Epub 2008/12/19. doi: 10.1021/jm801100v. PubMed PMID: 19090668; PubMed Central PMCID: PMCPMC2680181.

31. Cho Y, Crichlow GV, Vermeire JJ, Leng L, Du X, Hodsdon ME, et al. Allosteric inhibition of macrophage migration inhibitory factor revealed by ibudilast. Proc Natl Acad Sci USA. 2010;107(25):11313-8.

32. Fox RJ, Coffey CS, Cudkowicz ME, Gleason T, Goodman A, Klawiter EC, et al. Design, rationale, and baseline characteristics of the randomized double-blind phase II clinical trial of ibudilast in progressive multiple sclerosis. Contemp Clin Trials. 2016;50:166-77. doi: 10.1016/j.cct.2016.08.009. PubMed PMID: 27521810; PubMed Central PMCID: PMCPMC5035622.

33. Villegas-Mendez A, Strangward P, Shaw TN, Rajkovic I, Tosevski V, Forman R, et al. Gamma Interferon Mediates Experimental Cerebral Malaria by Signaling within Both the Hematopoietic and Nonhematopoietic Compartments. Infection and immunity. 2017;85(11):e01035-16. doi: 10.1128/IAI.01035-16. PubMed PMID: 28874445.

34. Tanese K, Hashimoto Y, Berkova Z, Wang Y, Samaniego F, Lee JE, et al. Cell Surface CD74-MIF Interactions Drive Melanoma Survival in Response to Interferon- $\gamma$. The Journal of investigative dermatology. 2015;135(11):2775-84. Epub 2015/06/04. doi: 10.1038/jid.2015.204. PubMed PMID: 26039541; PubMed Central PMCID: PMCPMC4640965.

35. Fernandez-Ruiz D, Lau LS, Ghazanfari N, Jones CM, Ng WY, Davey GM, et al. Development of a Novel CD4(+) TCR Transgenic Line That Reveals a Dominant Role for CD8(+) Dendritic Cells and CD40 Signaling in the Generation of Helper and CTL Responses to Blood-Stage Malaria. Journal of immunology (Baltimore, Md : 1950). 2017;199(12):416579. Epub 2017/11/01. doi: 10.4049/jimmunol.1700186. PubMed PMID: 29084838; PubMed Central PMCID: PMCPMC5713497.

36. Lopes da Silva M, Thieleke-Matos C, Cabrita-Santos L, Ramalho JS, Wavre-Shapton ST, Futter CE, et al. The host endocytic pathway is essential for Plasmodium berghei late liver stage development. Traffic (Copenhagen, Denmark). 2012;13(10):1351-63. Epub 2012/07/12. doi: 10.1111/j.1600-0854.2012.01398.x. PubMed PMID: 22780869.

37. Thuma PE, van Dijk J, Bucala R, Debebe Z, Nekhai S, Kuddo T, et al. Distinct clinical and immunologic profiles in severe malarial anemia and cerebral malaria in Zambia. The Journal of infectious diseases. 2011;203(2):211-9. Epub 2011/02/04. doi: 10.1093/infdis/jiq041. PubMed PMID: 21288821; PubMed Central PMCID: PMCPMC3071068. 
Figure 1

A

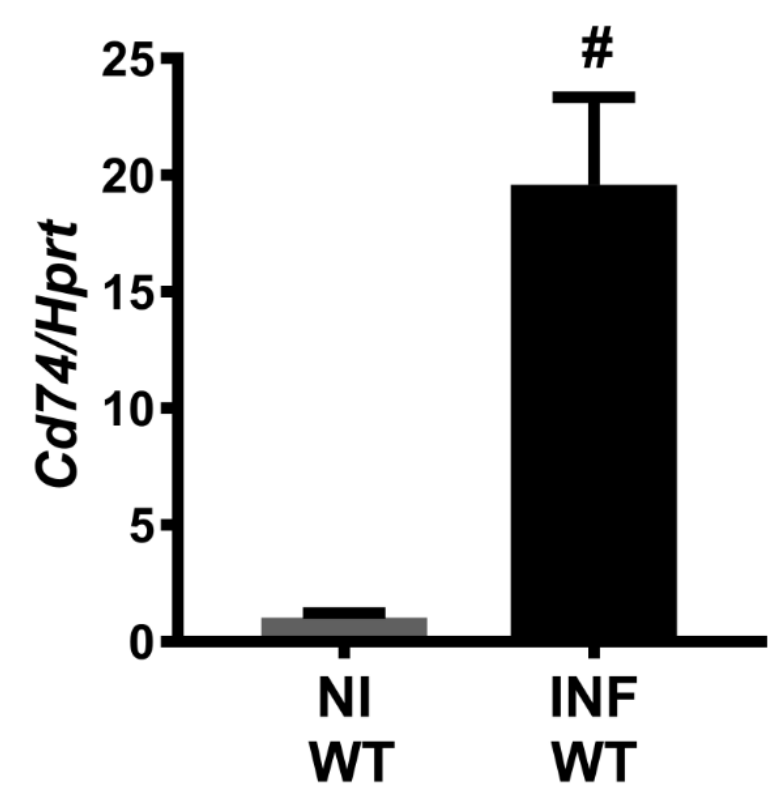

D
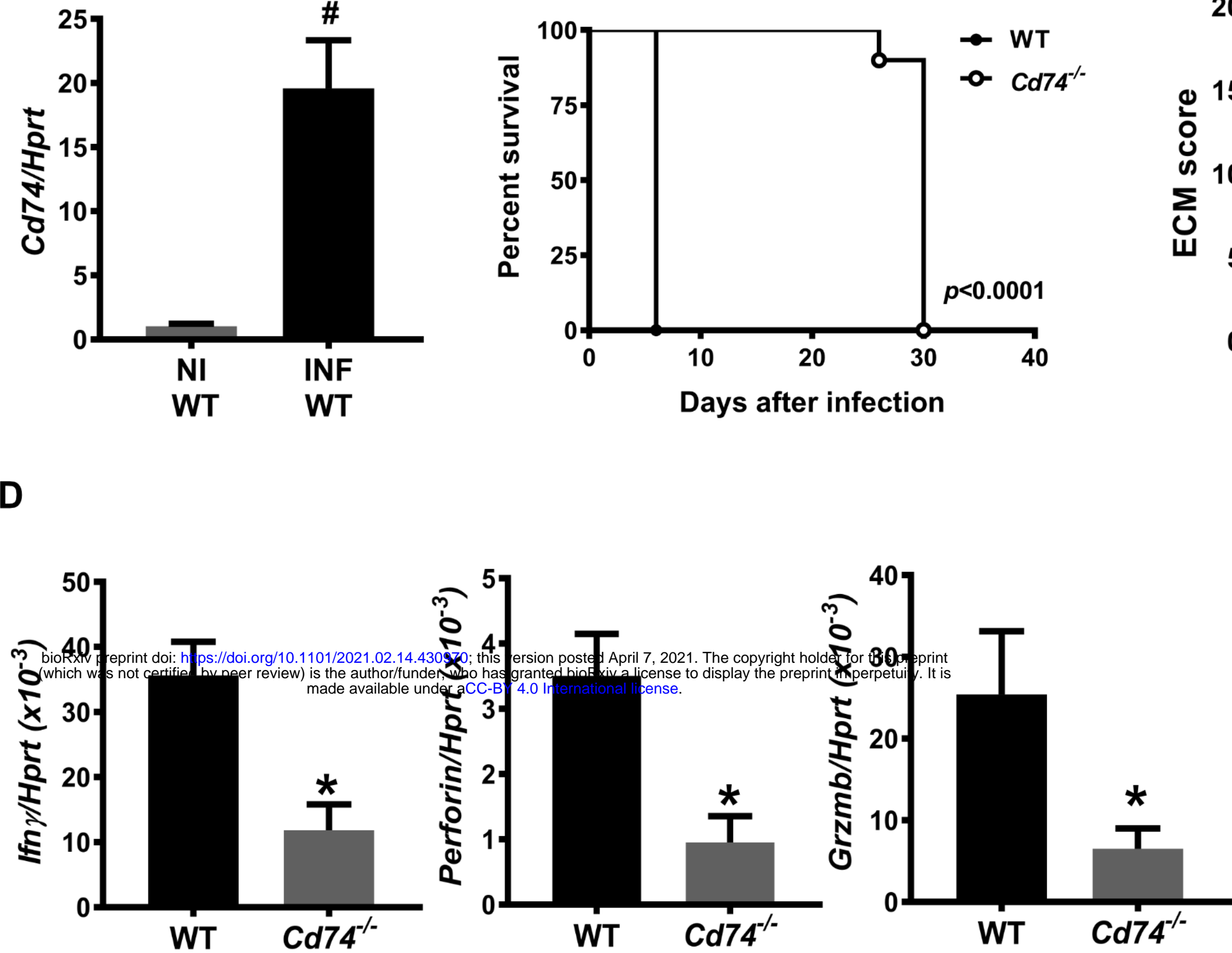

C

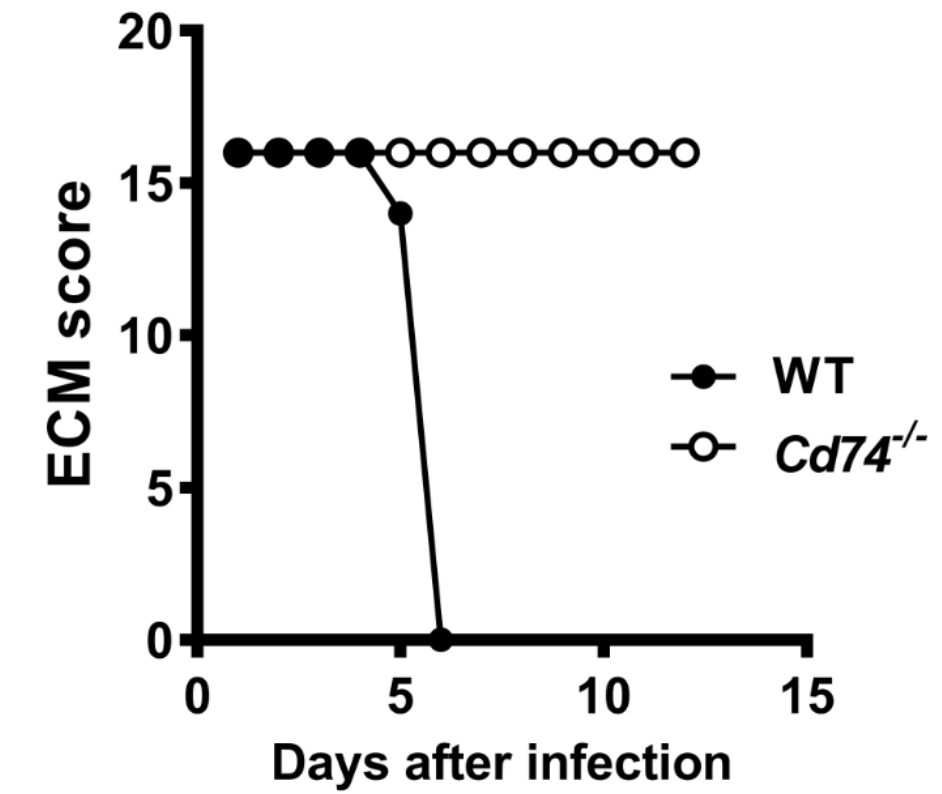

$\mathbf{F}$

G

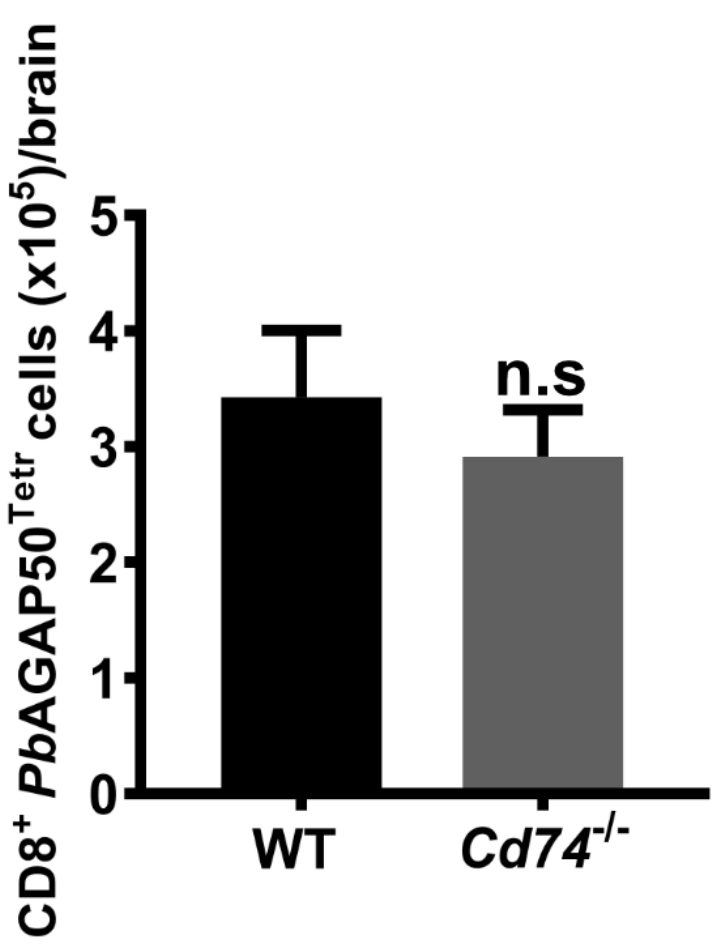

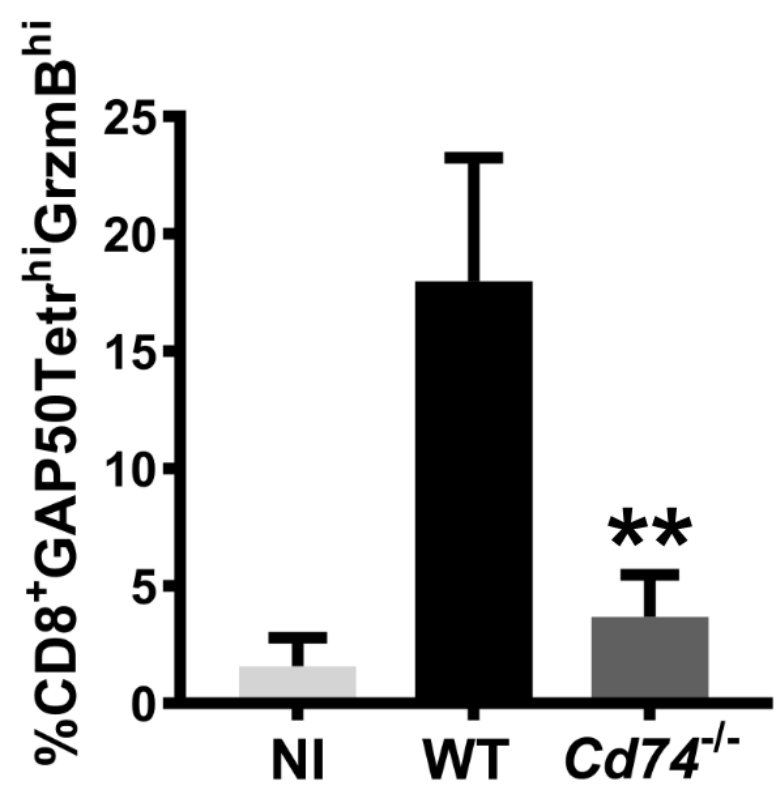
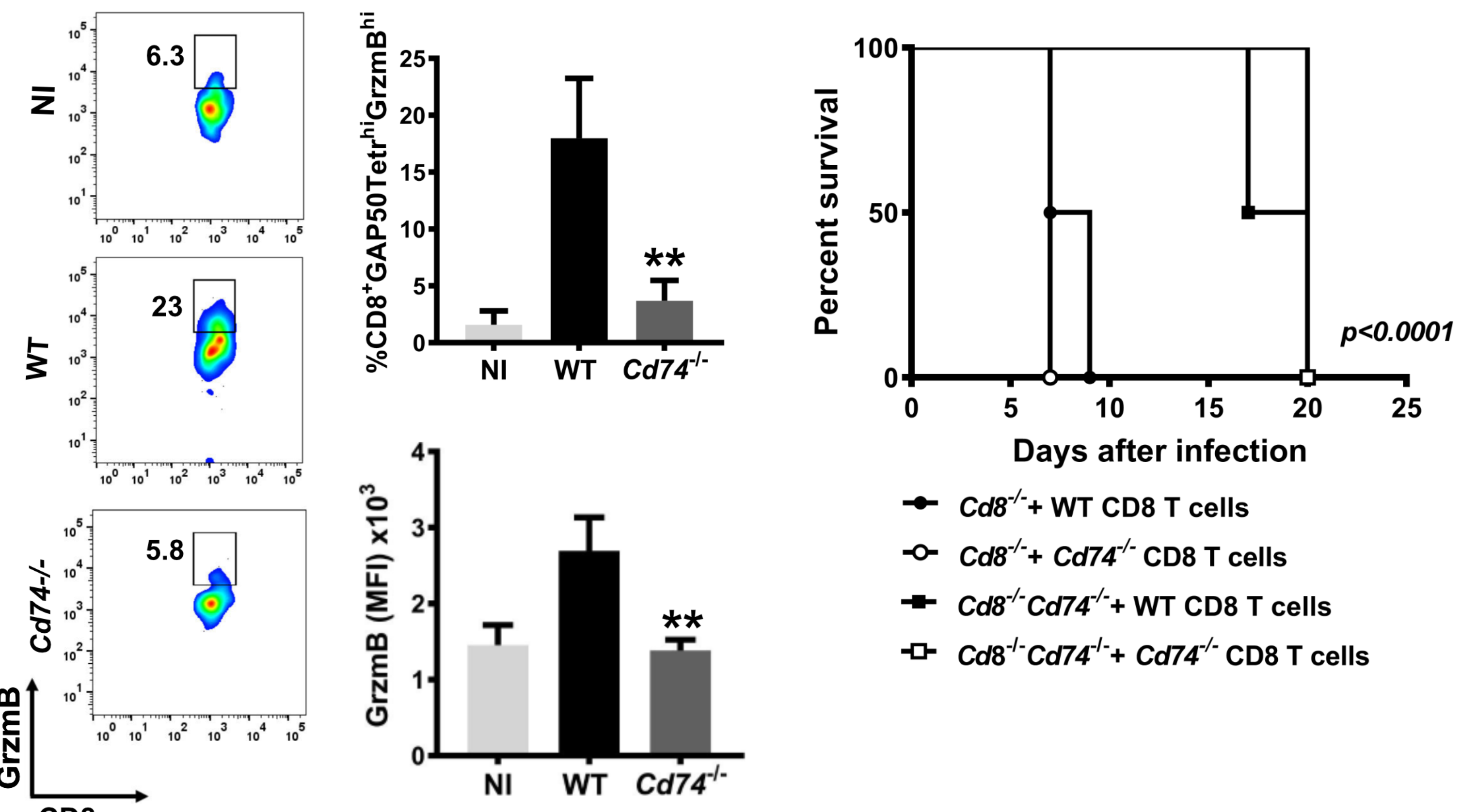

Days after infection

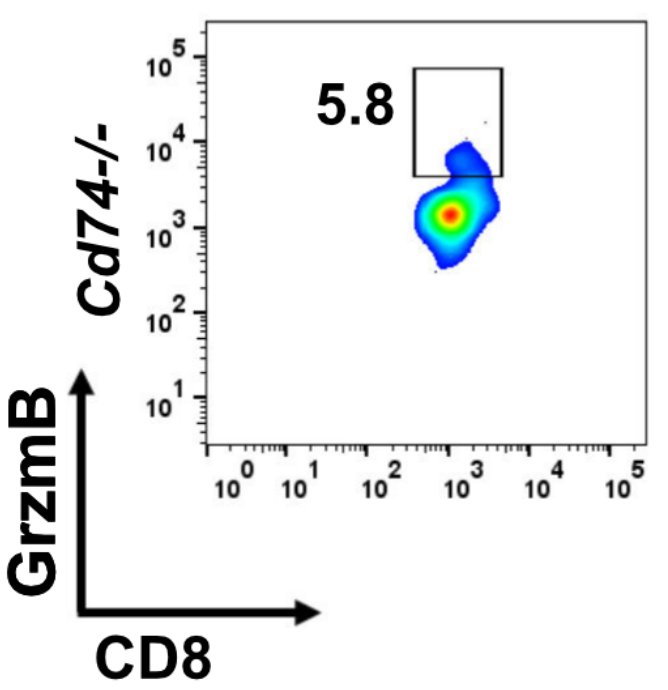

$\rightarrow \mathrm{Cd}^{-/-}+$WT CD8 T cells

$-\infty \mathrm{Cd}^{-/-}+\mathrm{Cd}^{-1 /-} \mathrm{CD} 8 \mathrm{~T}$ cells

$\rightarrow \mathrm{Cd} 8^{-/-} \mathrm{Cd} 74^{-/}+$WT CD8 T cells

$-\square-\mathrm{Cd}^{-/-} \mathrm{Cd} 74^{-/-}+\mathrm{Cd} 74^{-/-} \mathrm{CD} 8 \mathrm{~T}$ cells 
Figure 2

A

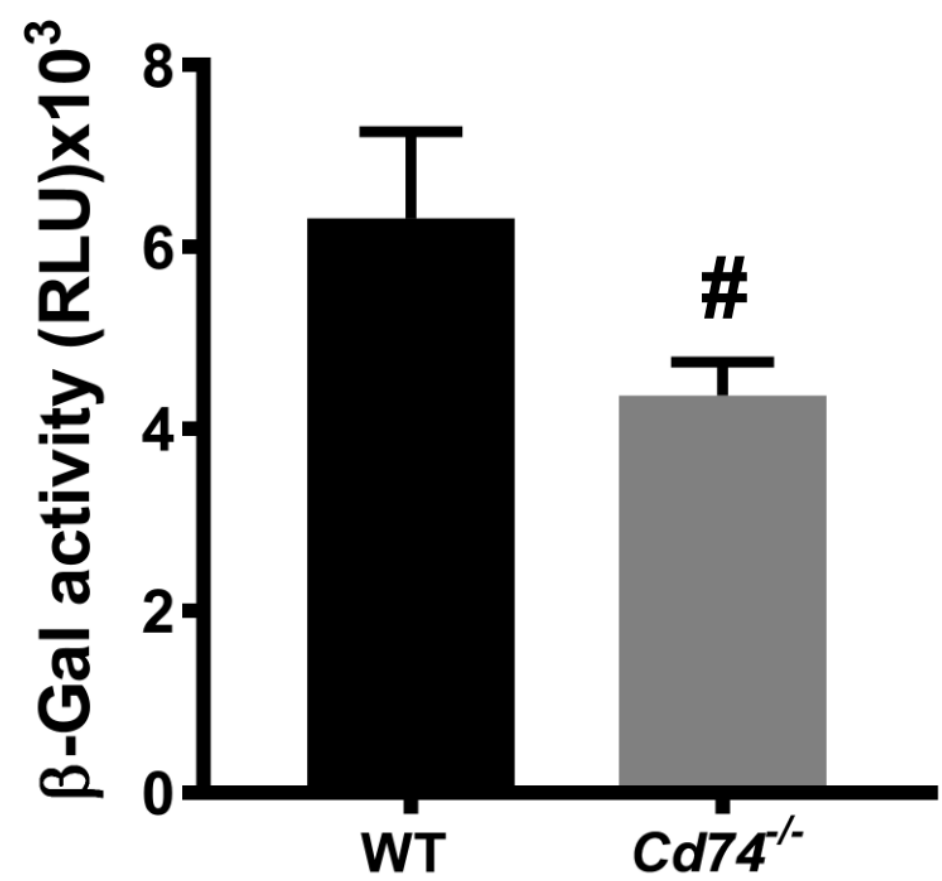

B

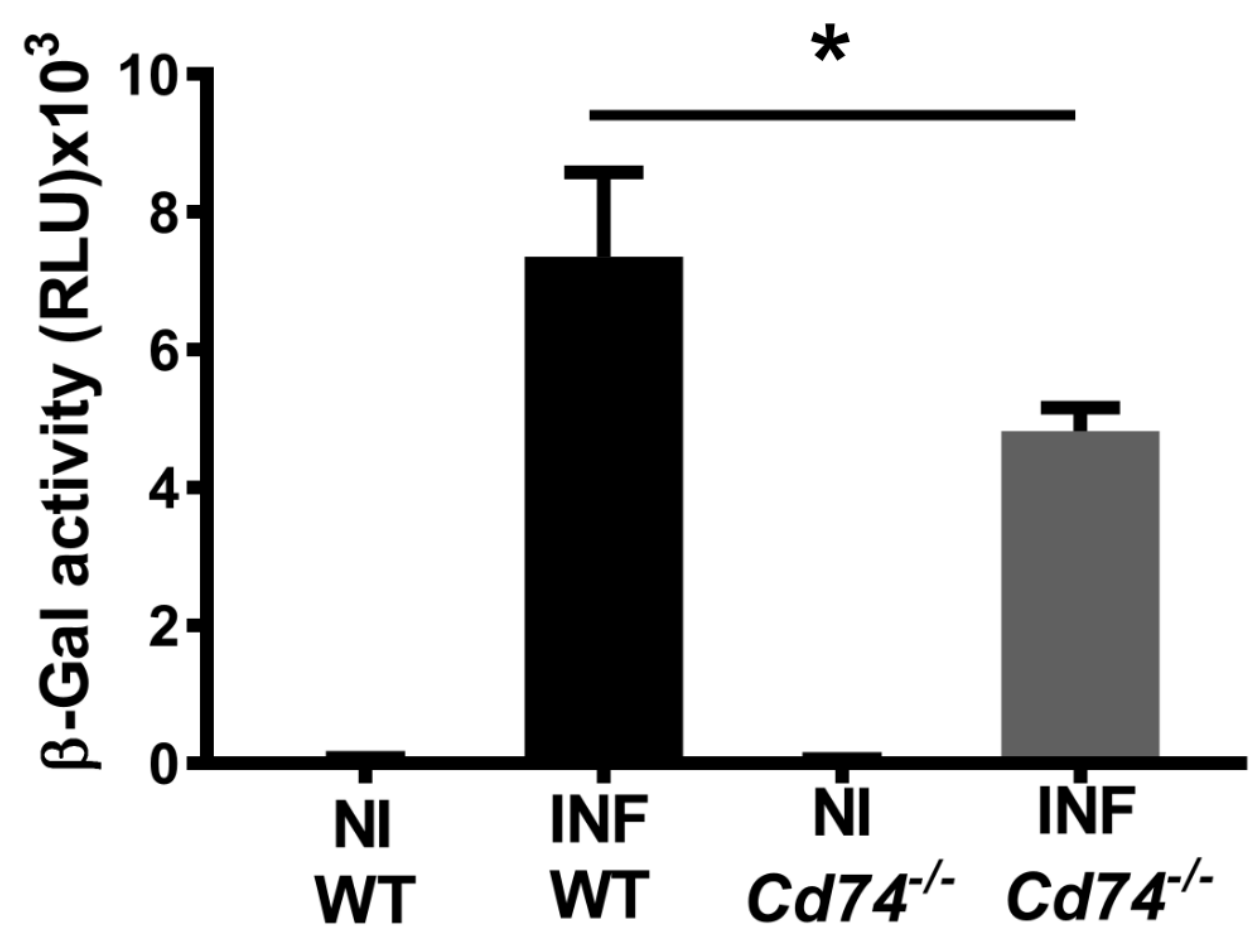

bioRxiv preprint doi: https://doi.org/10.1101/2021.02.14.430970; this version posted April 7, 2021. The copyright holder for this preprint
(which was not certified by peer review) is the author/funder, who has granted bioRxiv a license to display the preprint in perpetuity. It is made available under aCC-BY 4.0 International license.

C

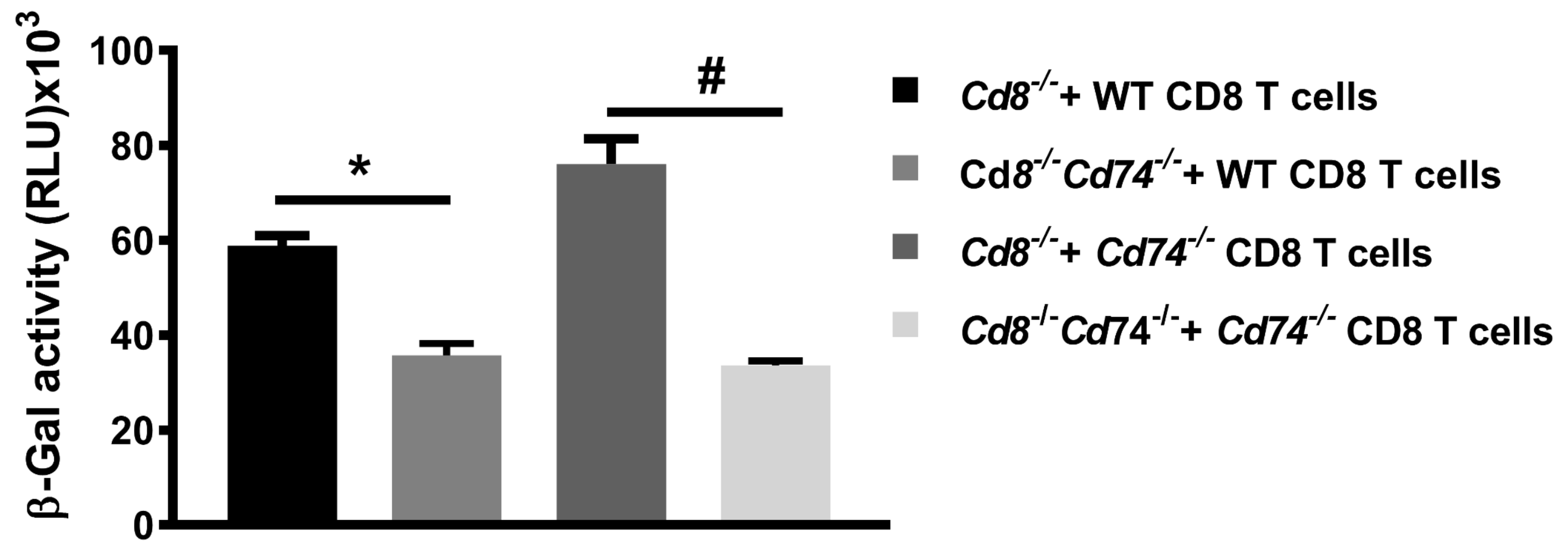


Figure 3

A

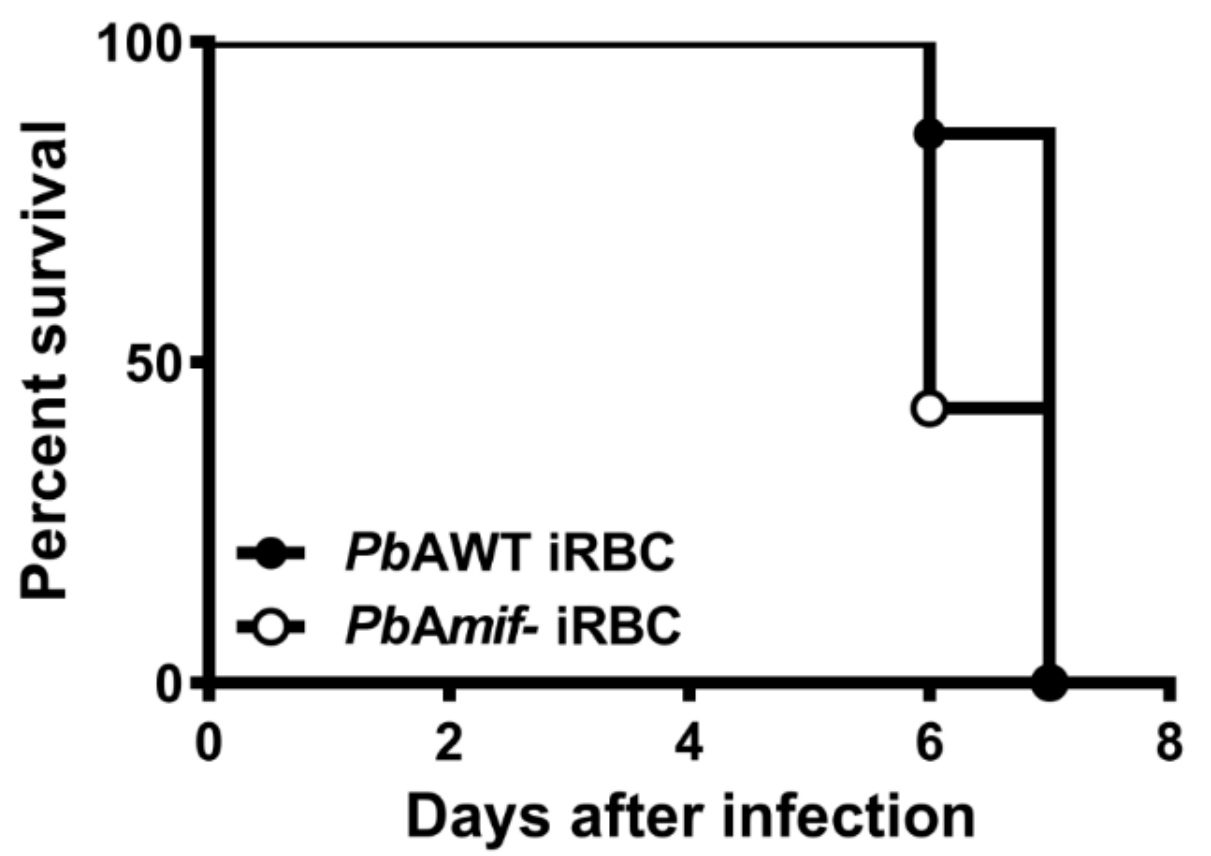

B

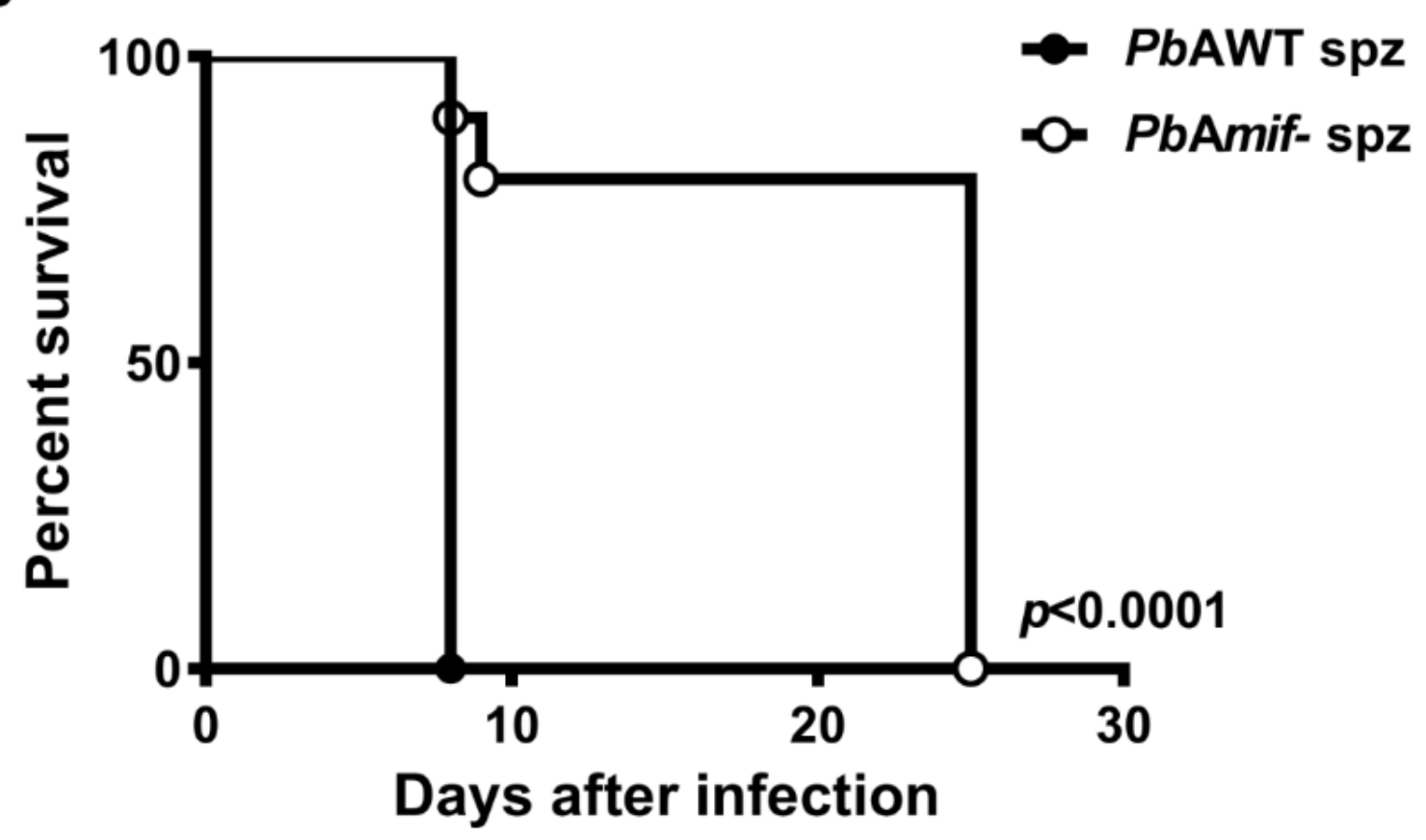

C

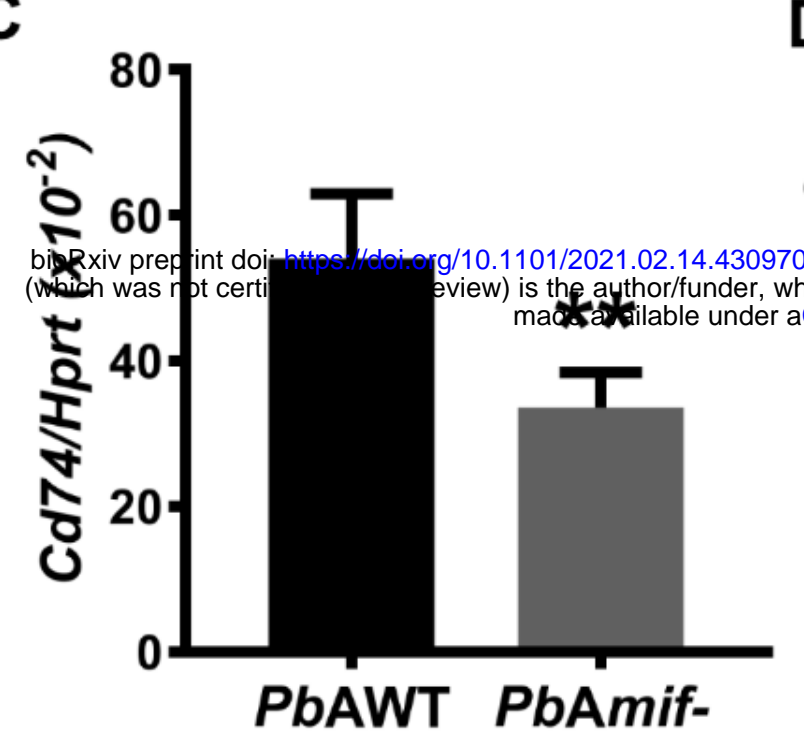

D
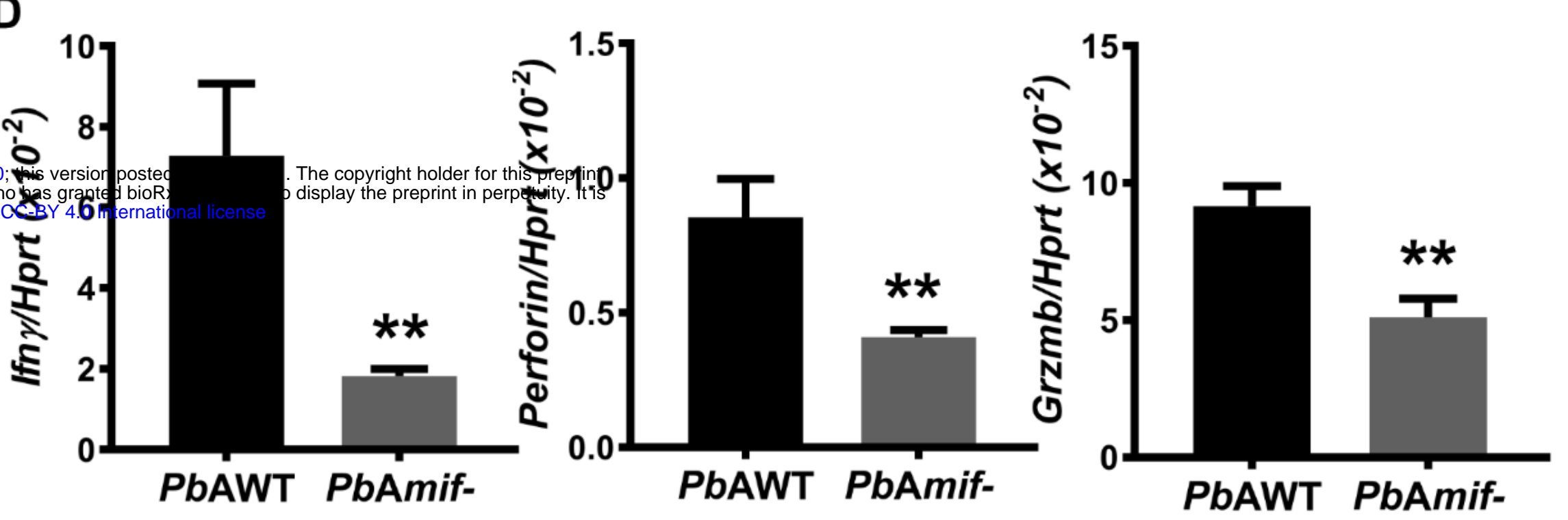

E

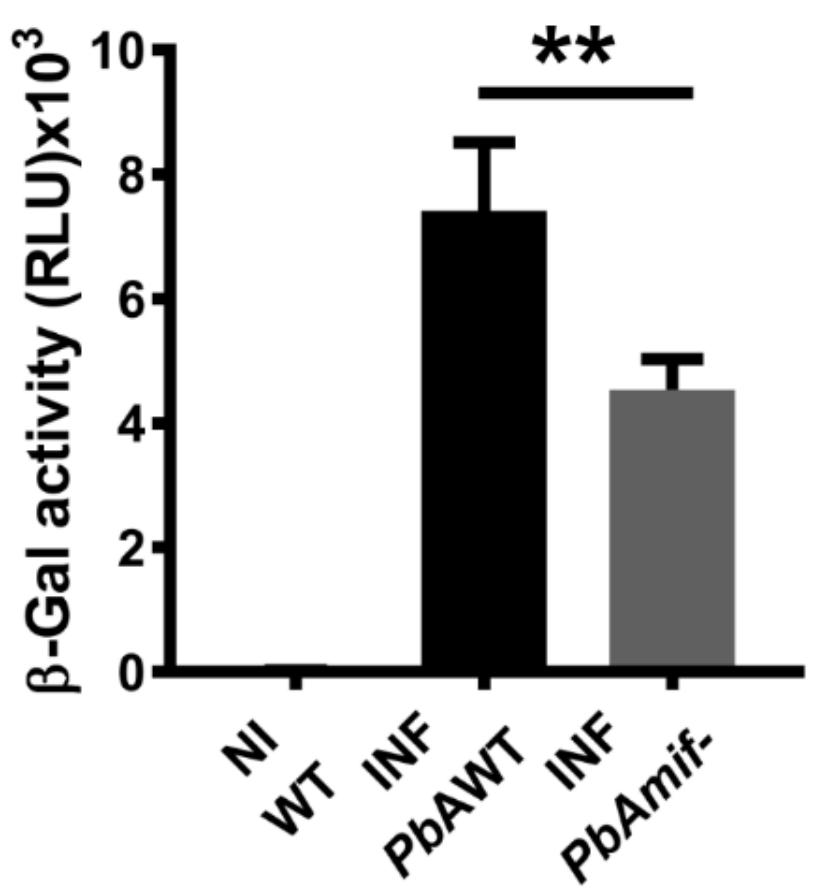




\section{Figure 4}

A

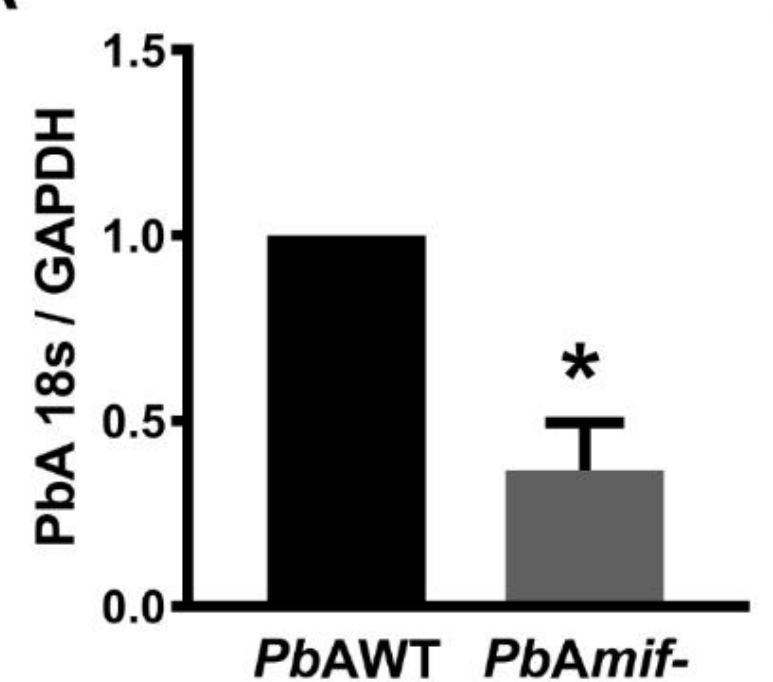

C

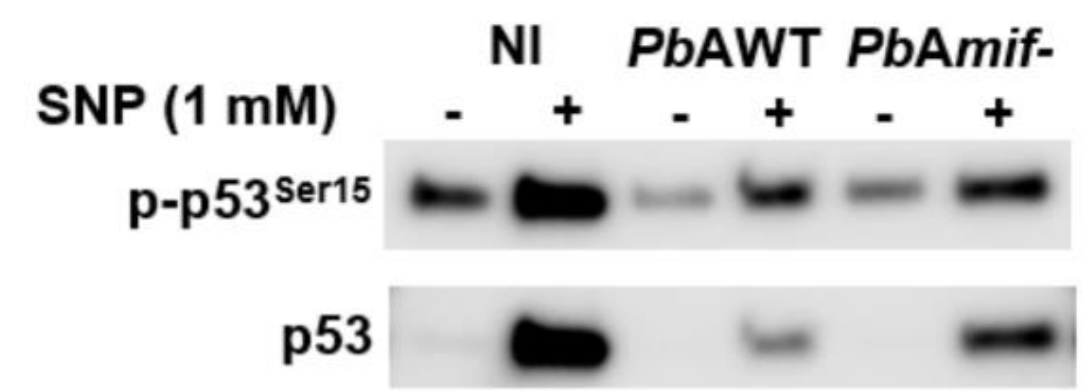

bioRxiv preprint doi: https://doi.org/10.1101/2021.02.14.430970; this version posted April 7, 2021. The copyright holder for this preprint $\beta$-Actin

$$
0.51 .30 .260 .60 .241 \quad p-p 53 / \beta-A c t i n
$$

D

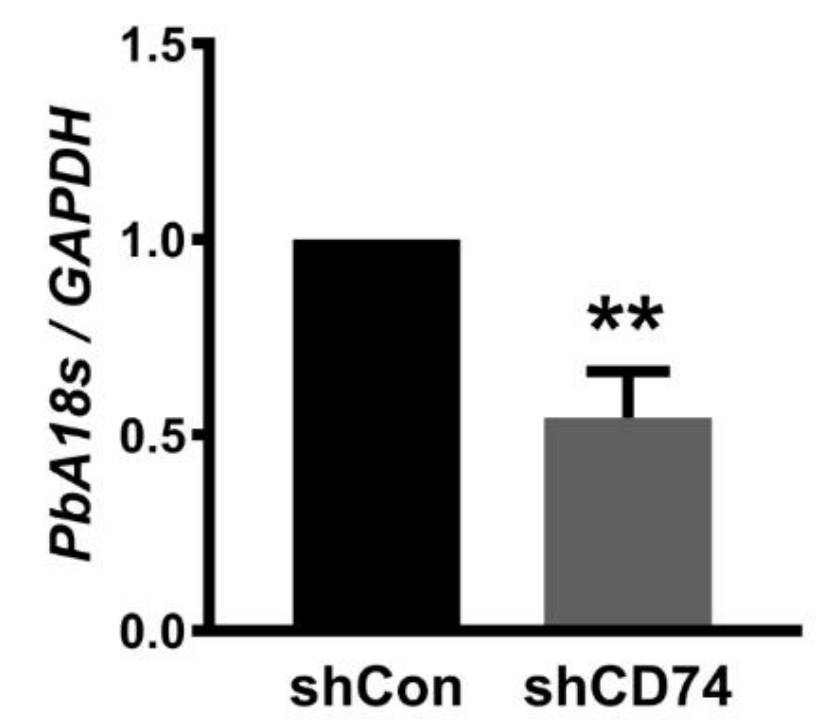

$\mathbf{F}$

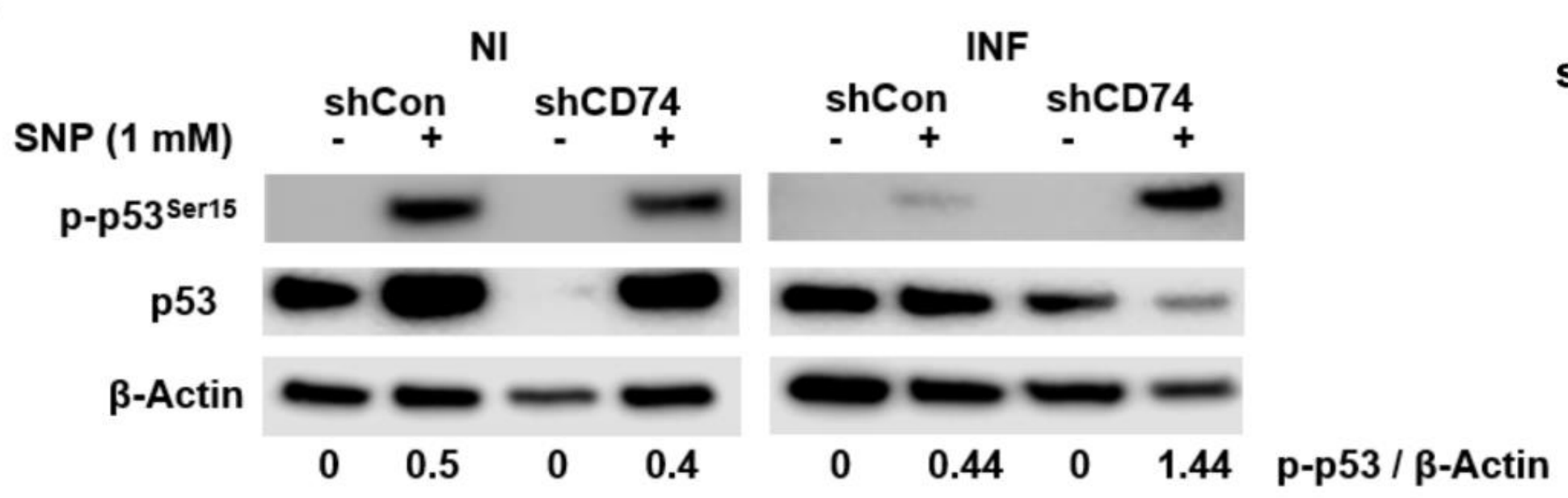

E
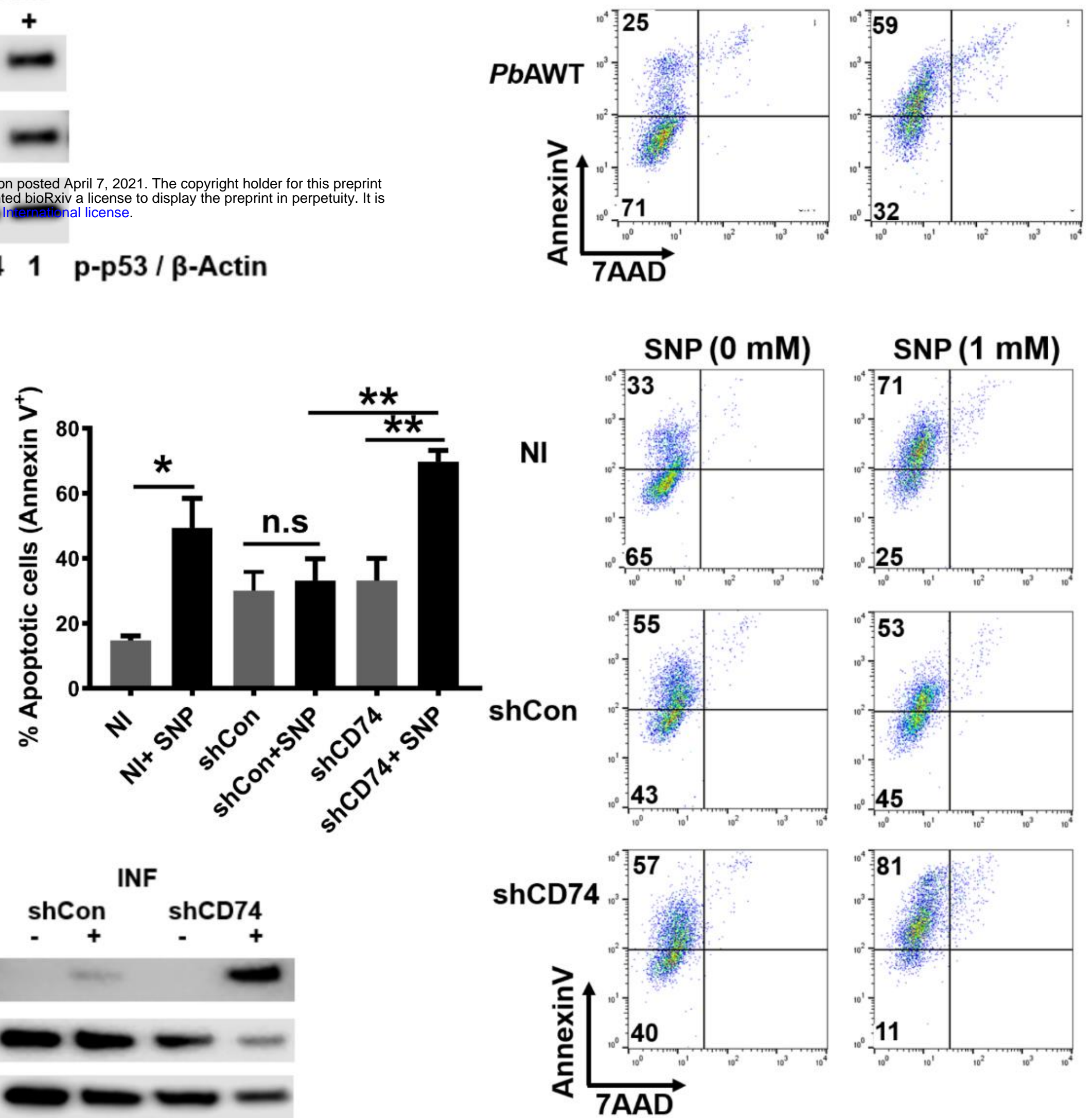

G
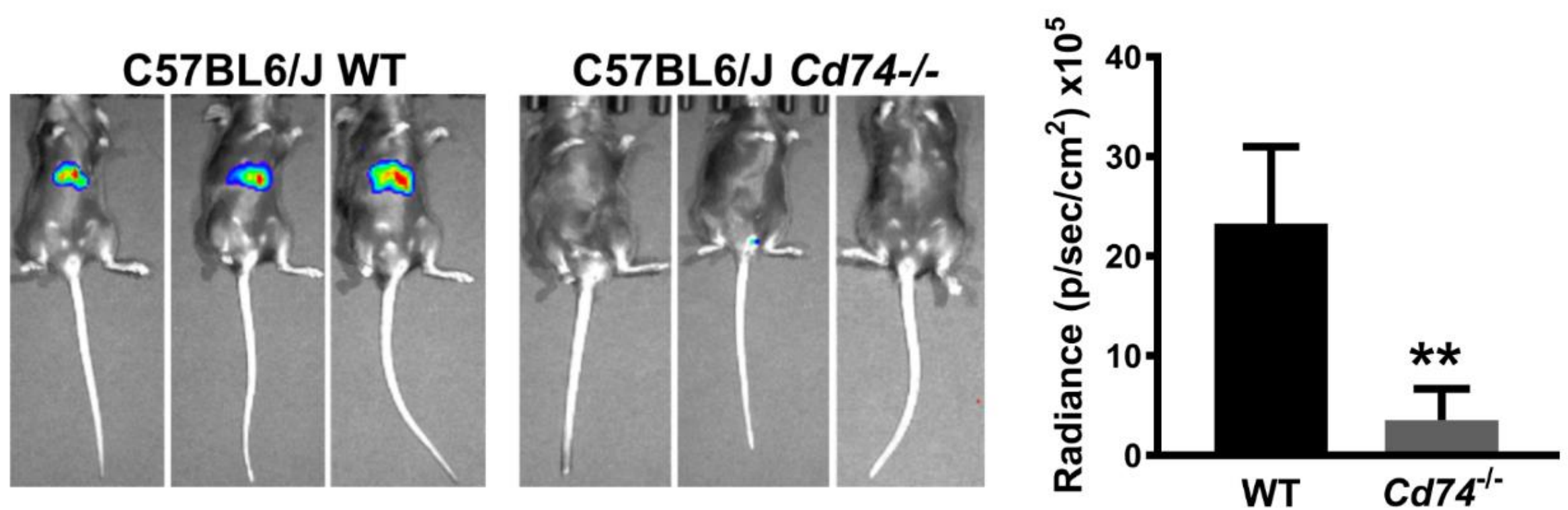
Figure 5

A

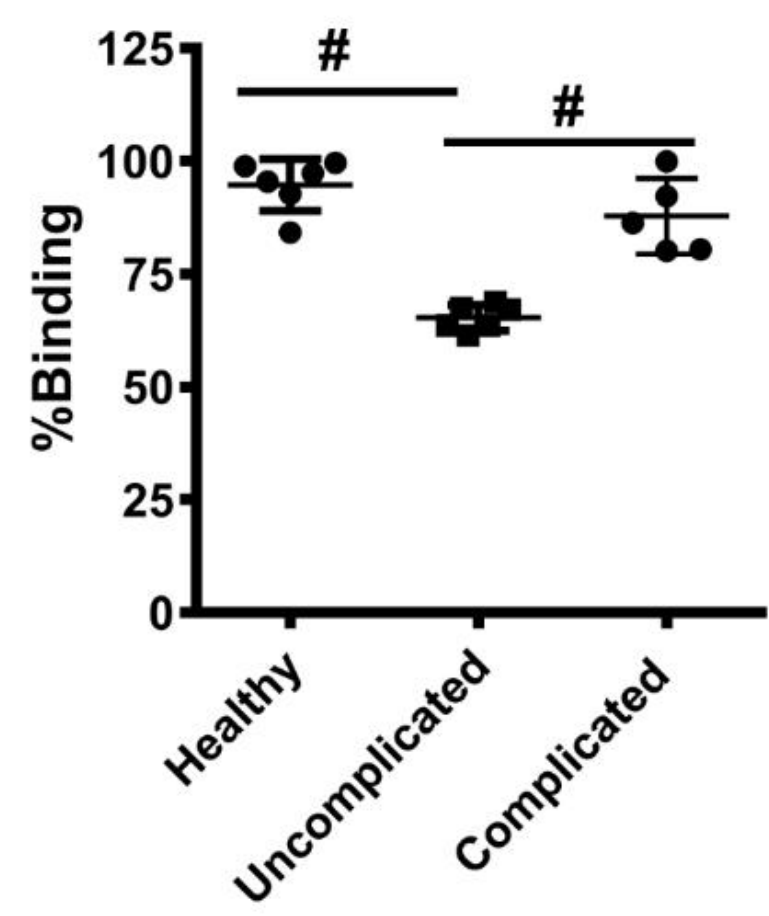

B
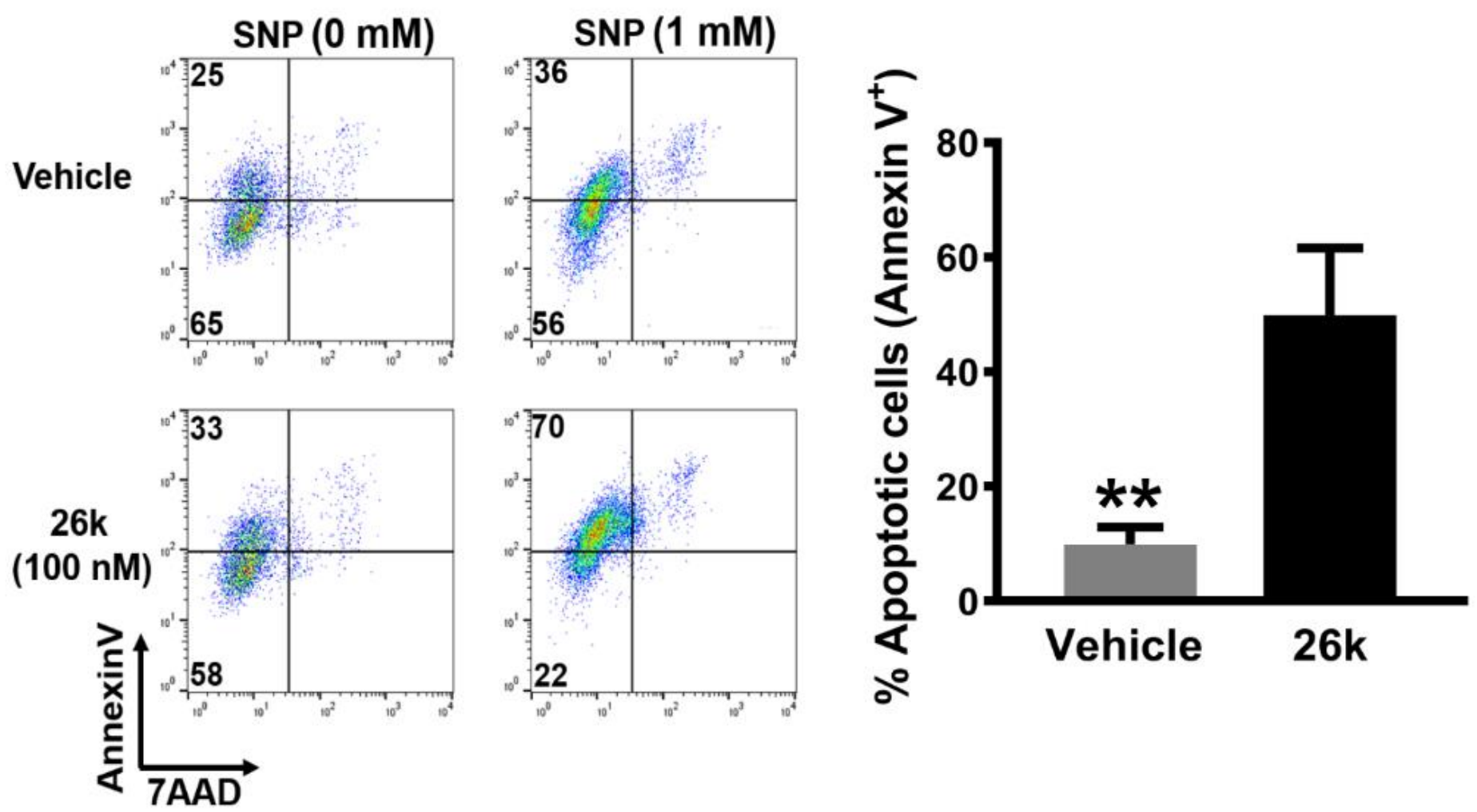

C

DMSO

26k

$\frac{100 \mathrm{nM}}{10 \mathrm{nM}} \frac{100 \mathrm{nM}}{10 \mathrm{nM}}$

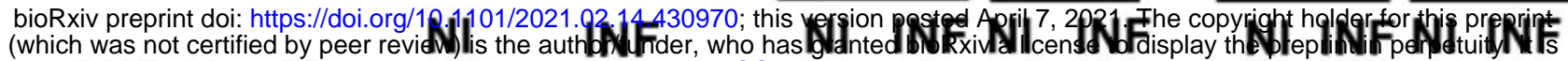

SNP (1 mM) - mpde available 4 nder aCC-B

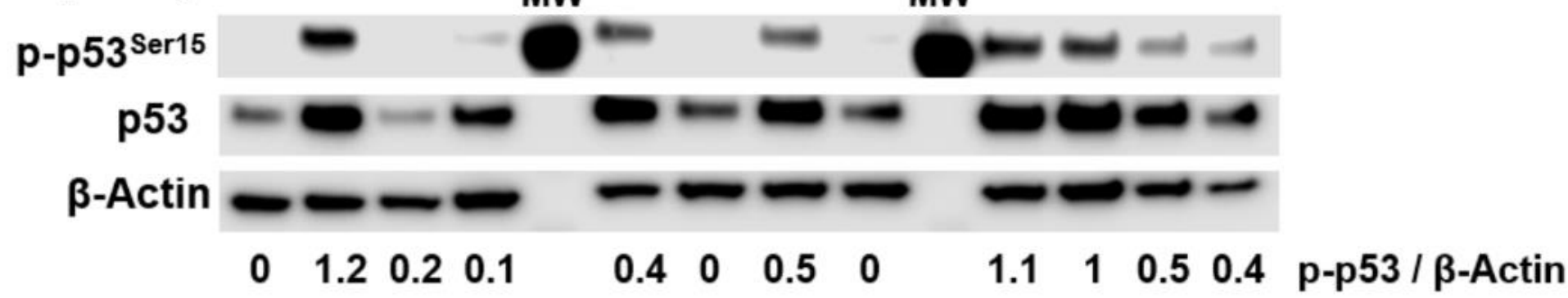

$\mathbf{E}$
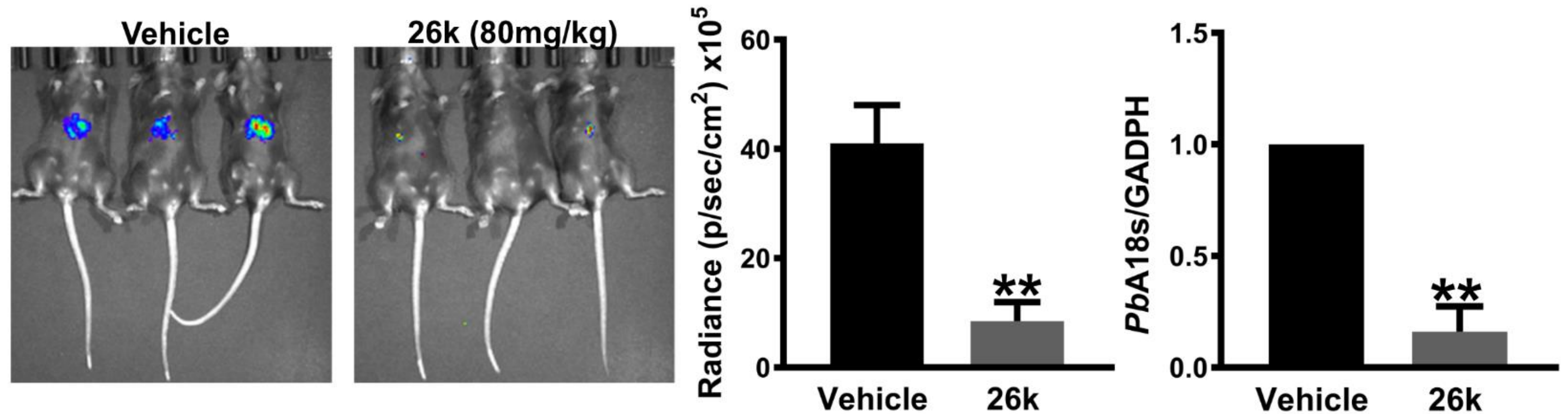

$\mathbf{F}$

G
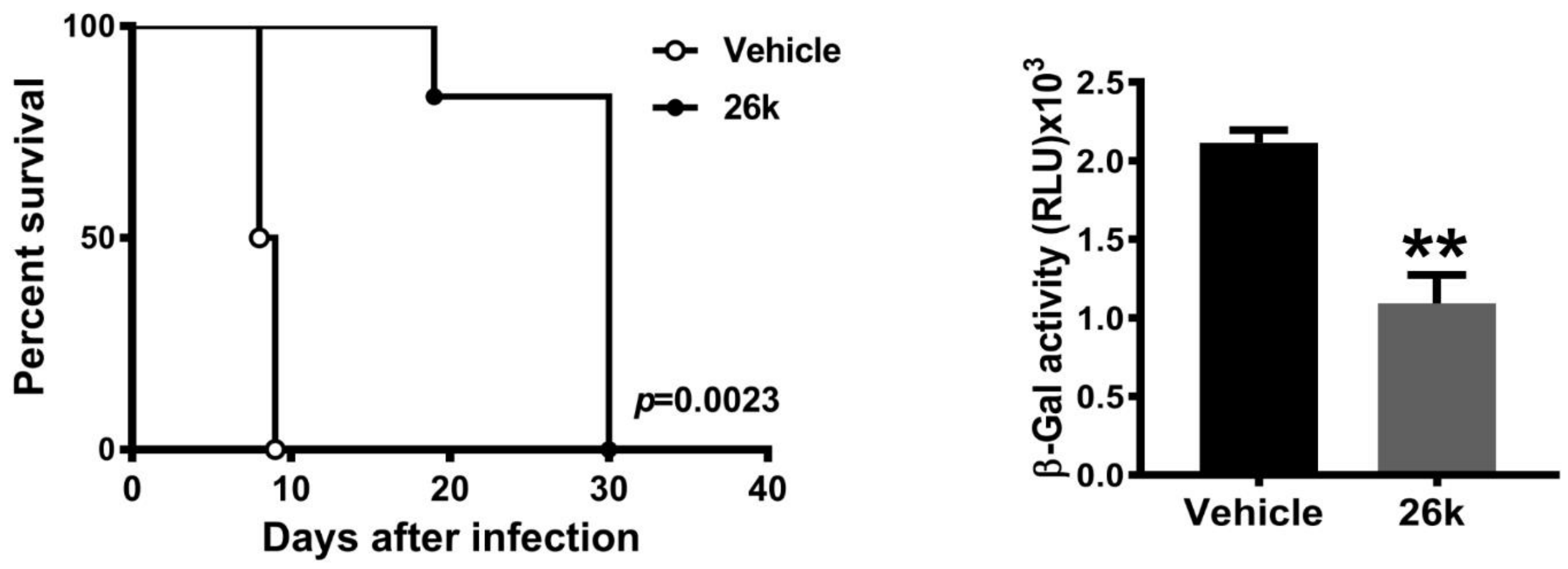


\section{Figure S1}

A

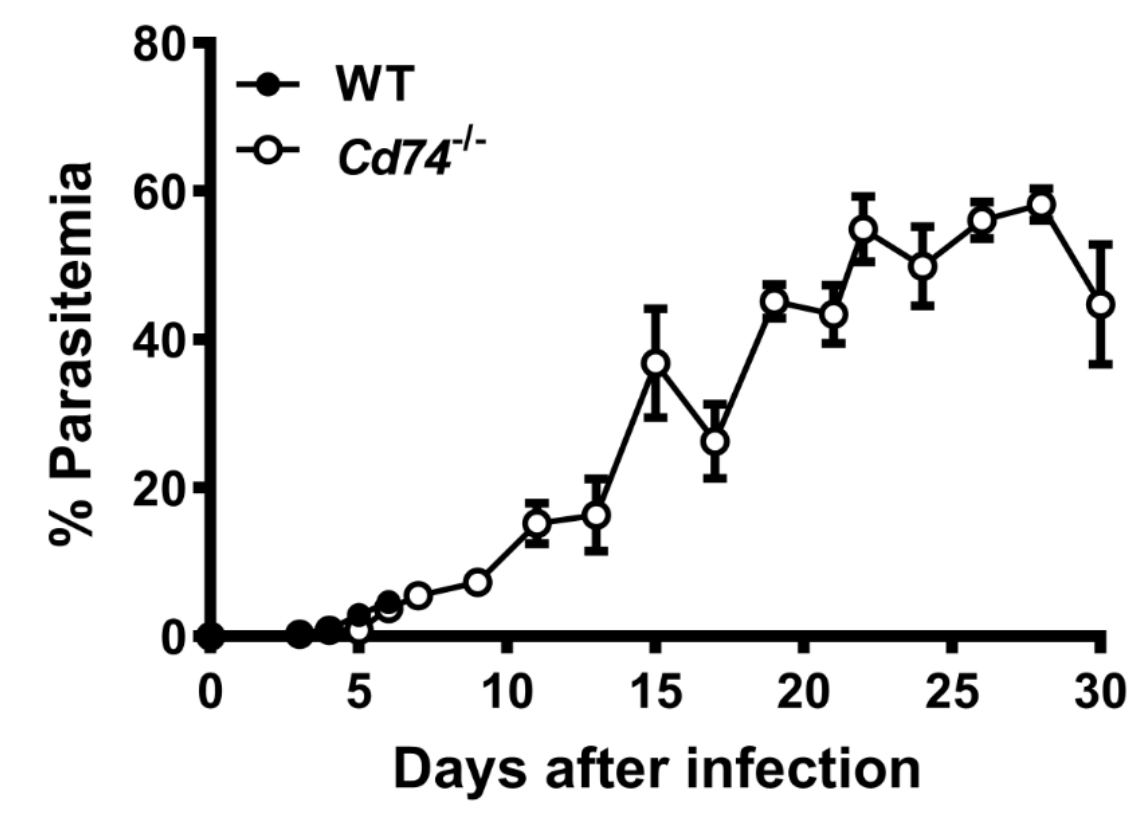

C

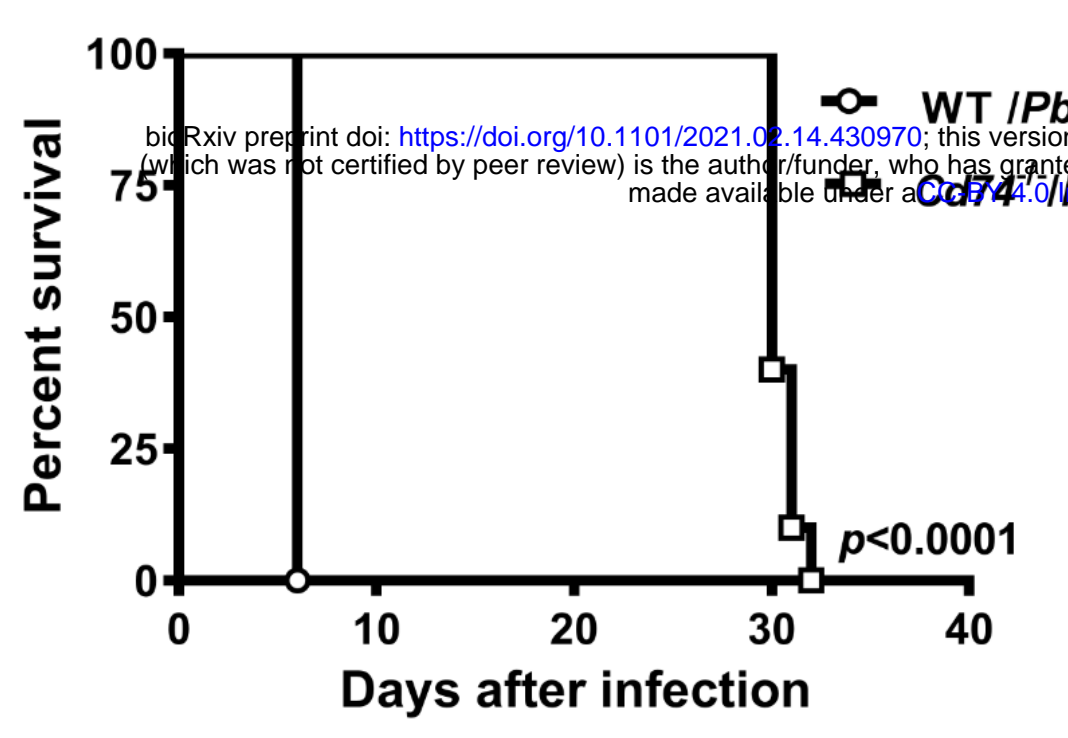

F

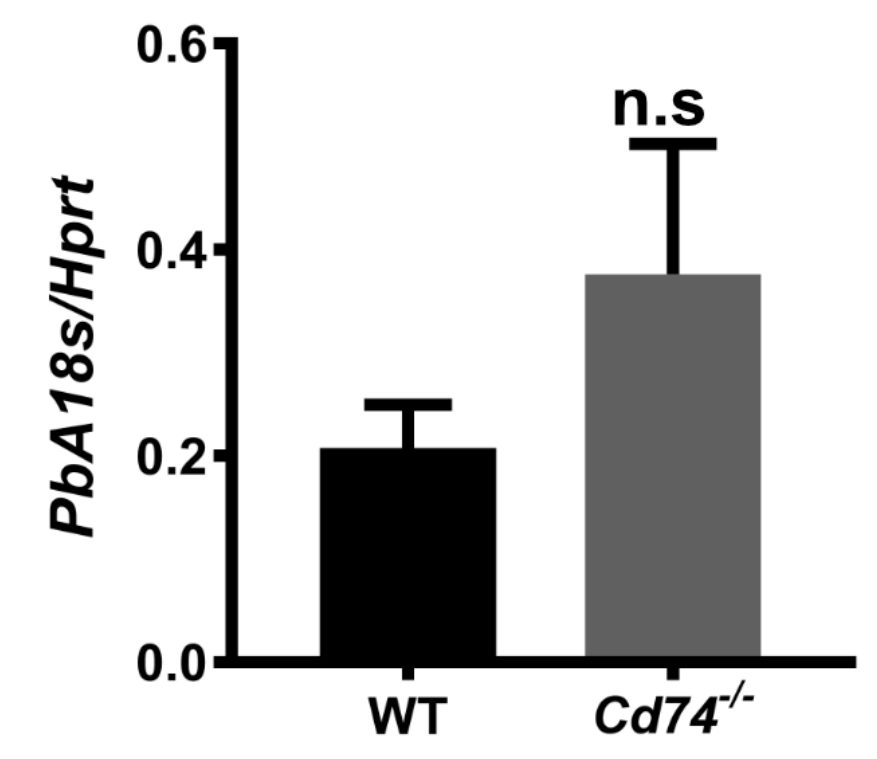

B

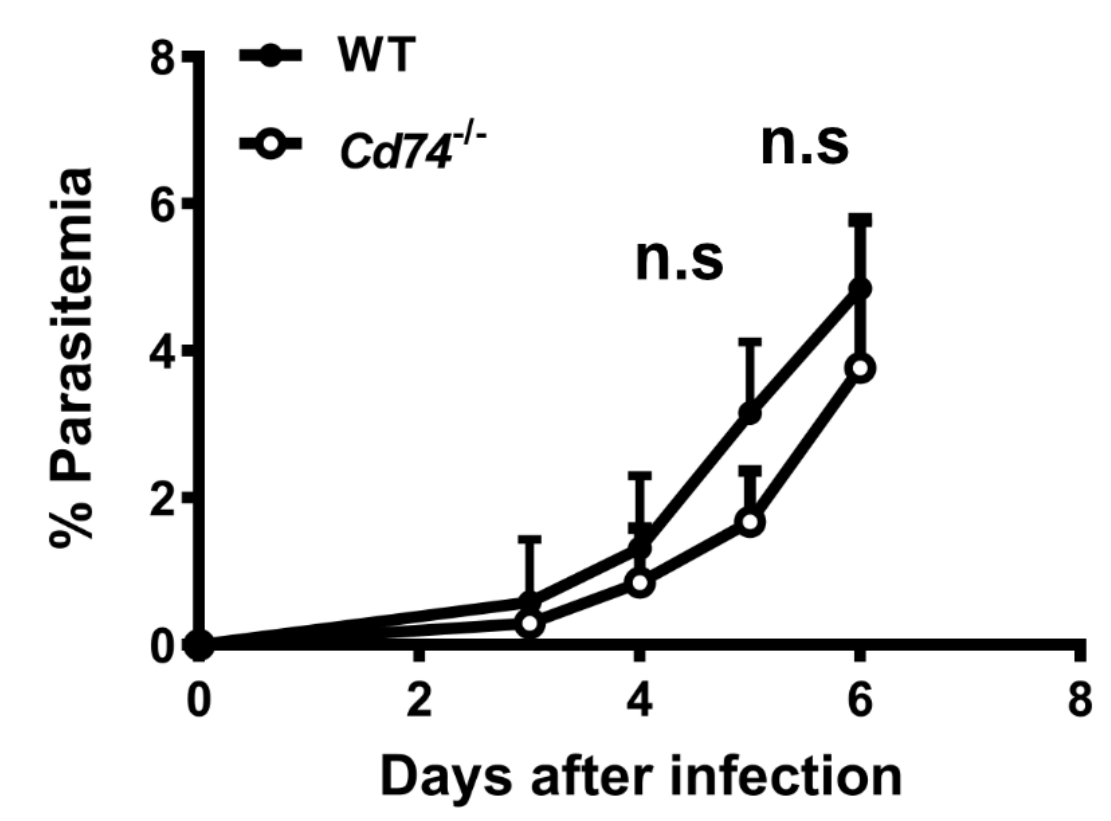

D

E

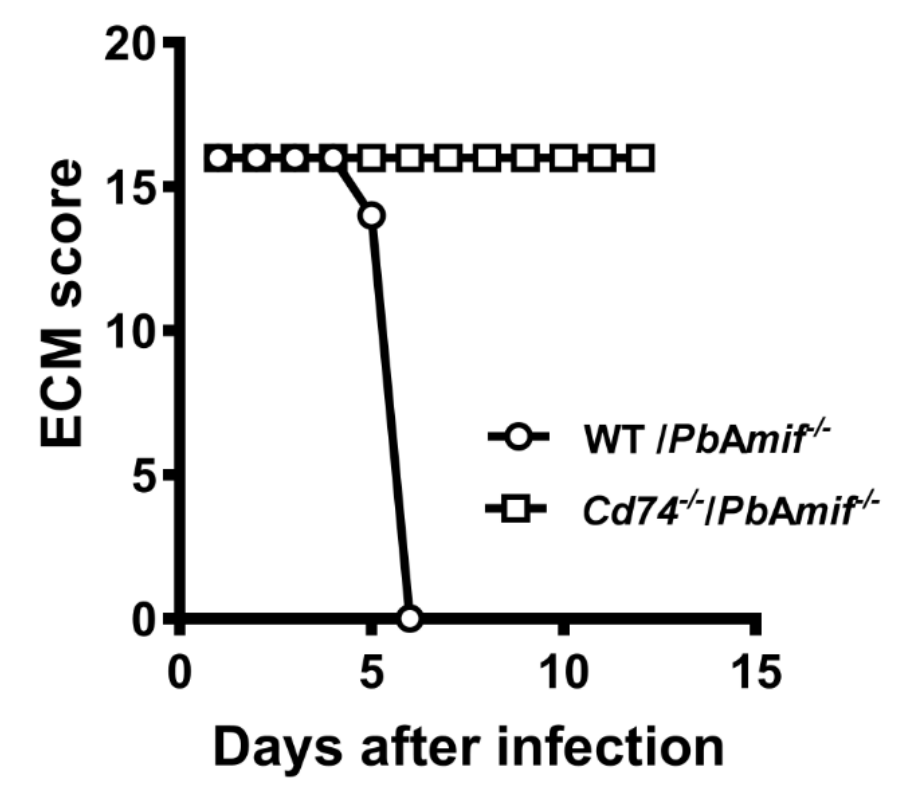


Figure S2

A

B

24h

48h

PbAWT PbAmif- PbAWT PbAmif-

MSP-1

PbAWT PbAmif-

CSP
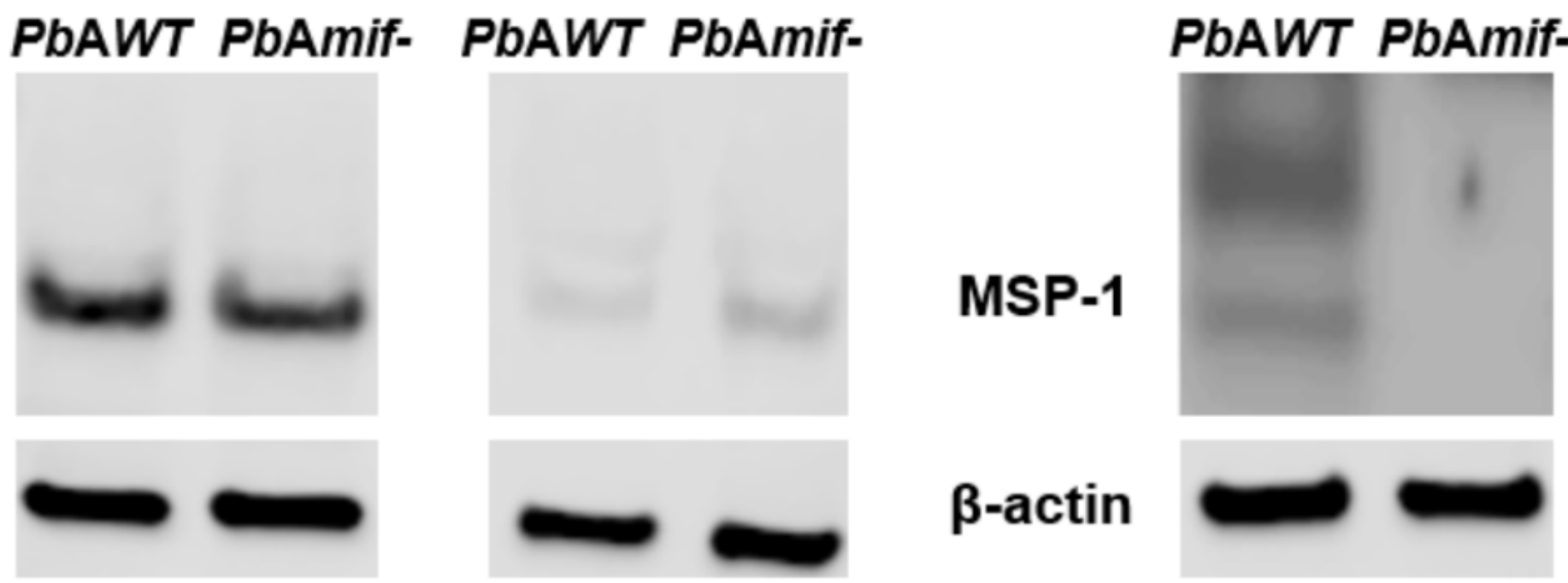

MSP-1

PbAWT PbAmif-

$\beta$-actin

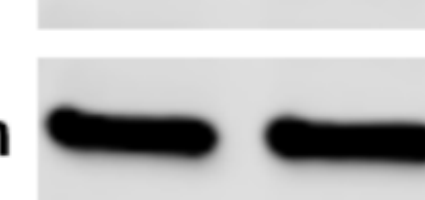

C

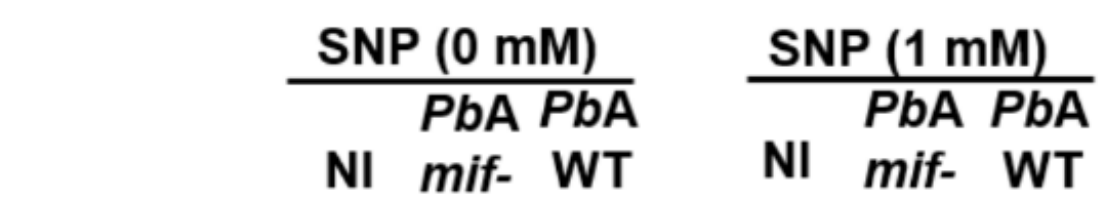

p-Aktser473

bioRxiv preprint doi: https://doi.org/10.1101/2021.02.14.430970; this version posted April 7, 2021. The copyright holder for this preprint

Akt

$\beta$-Actin

$\begin{array}{lll}0.3 & 0.4 & 0.24\end{array}$

$0.4 \quad 0.27 \quad 0.56 \quad p-A k t / \beta-A c t i n$

D
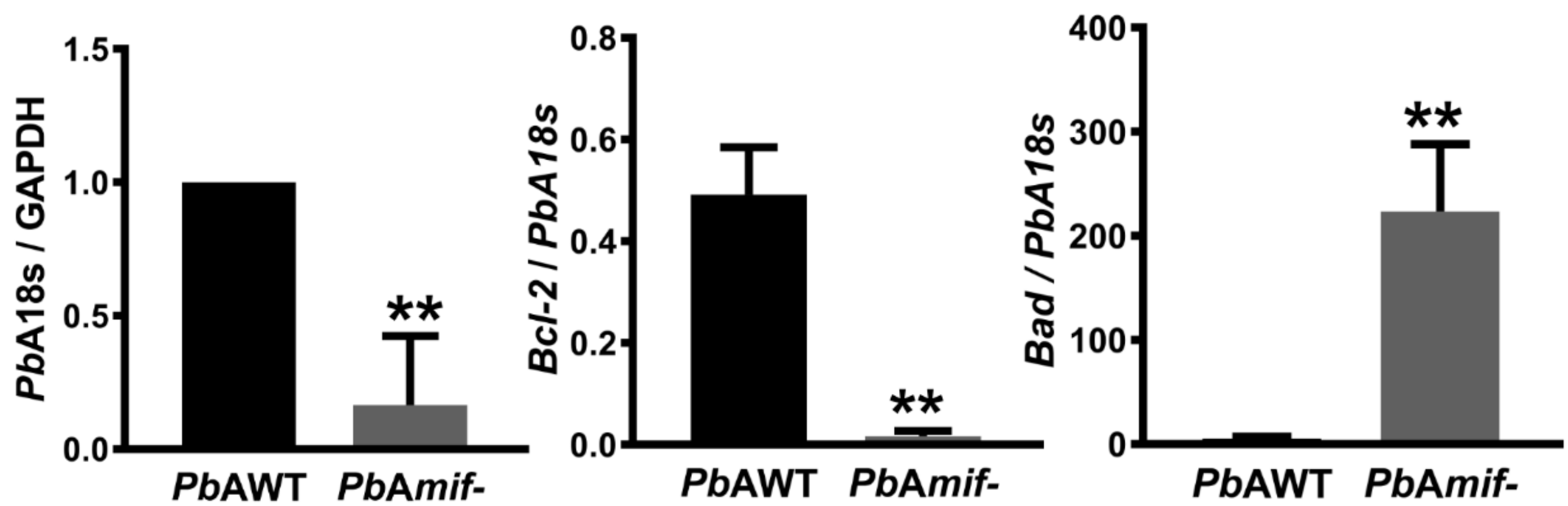

E

F
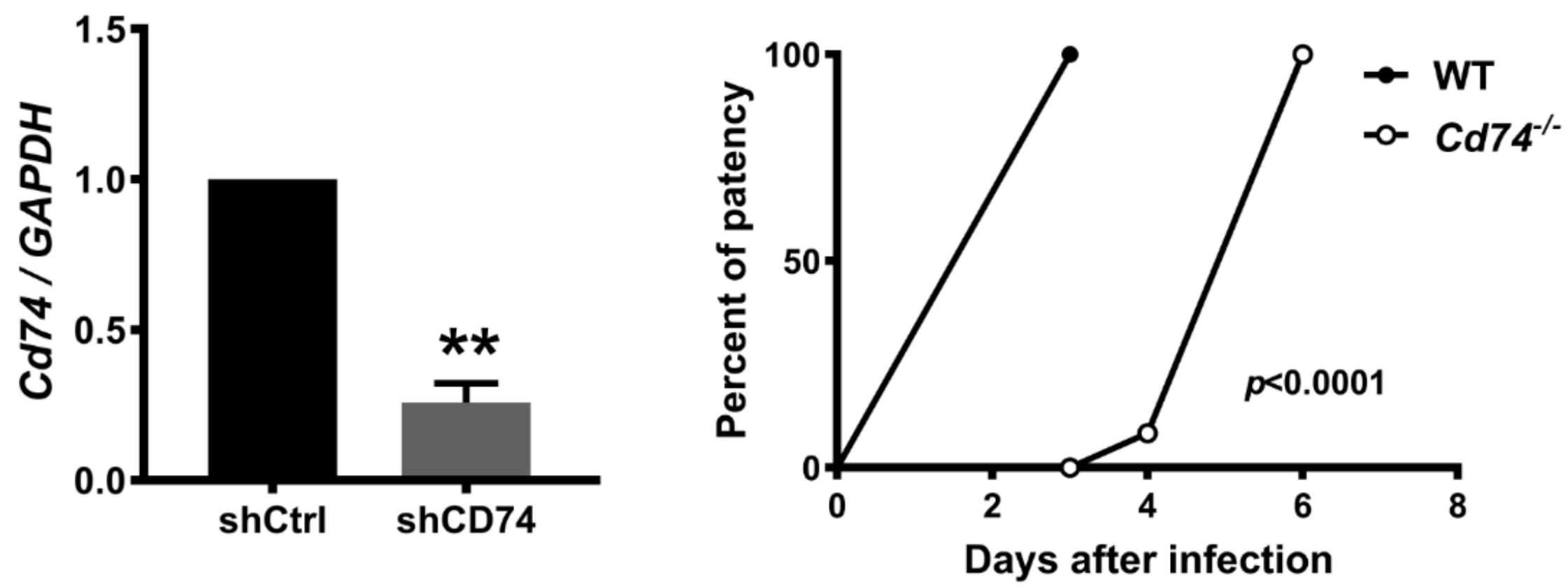
Figure S3

A

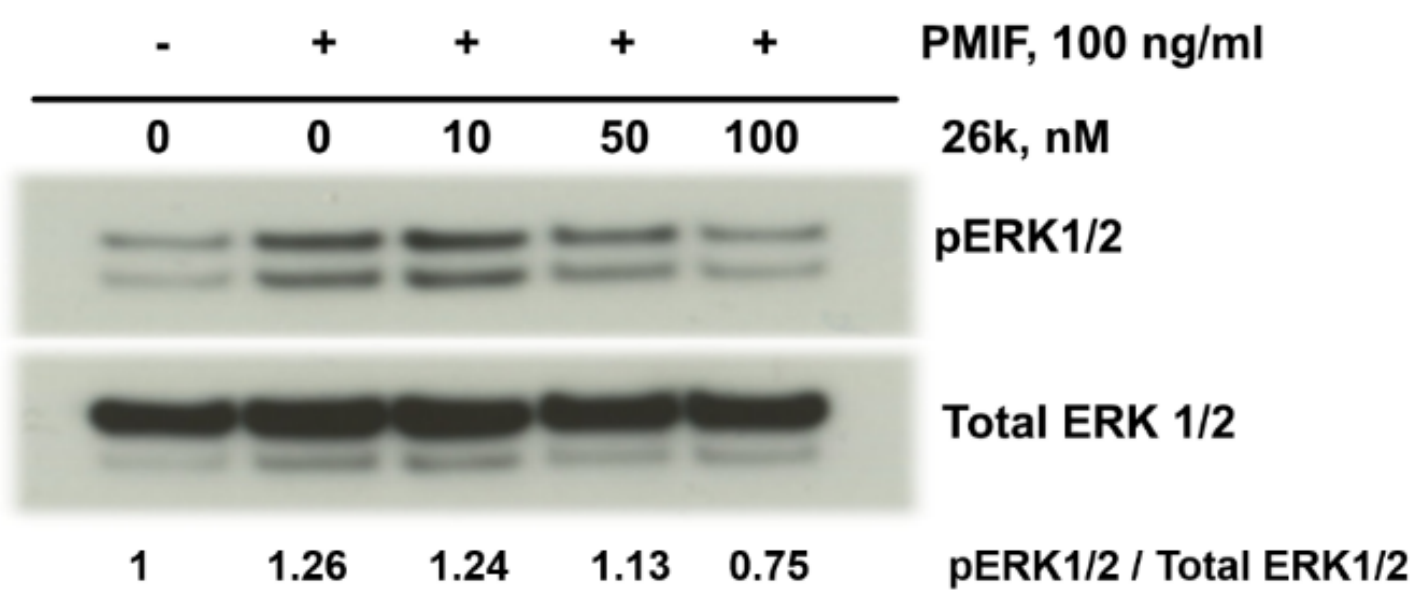

C

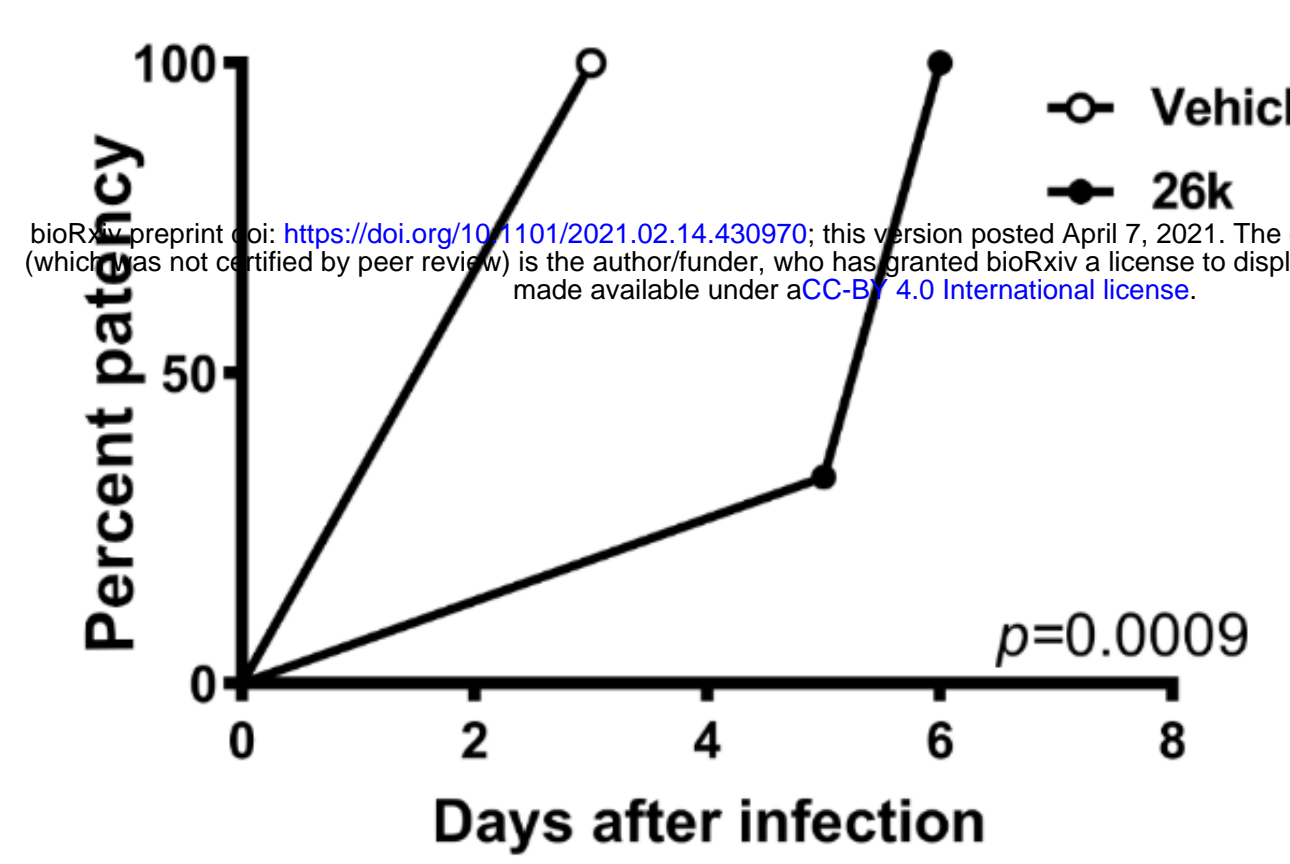

E

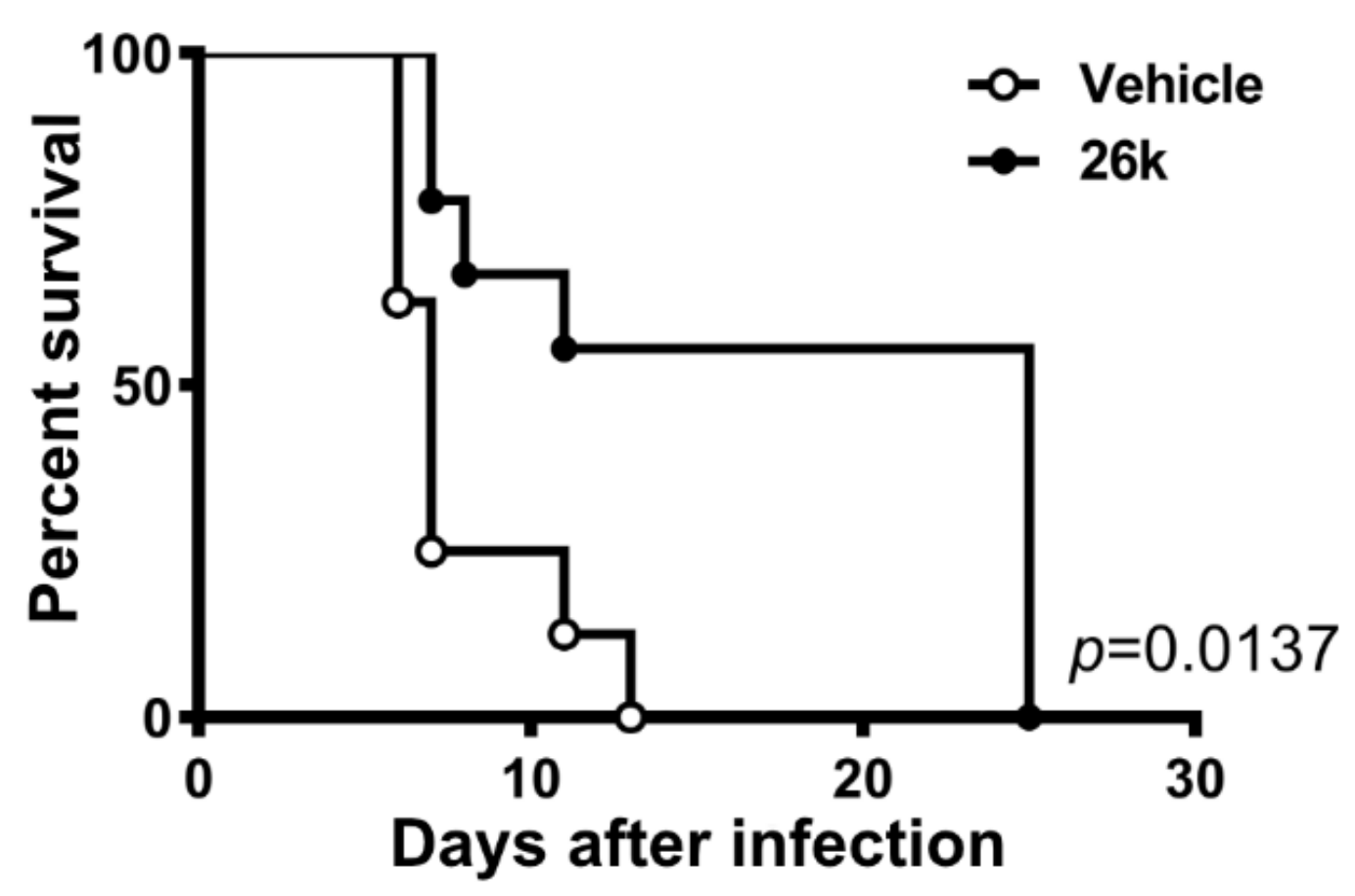

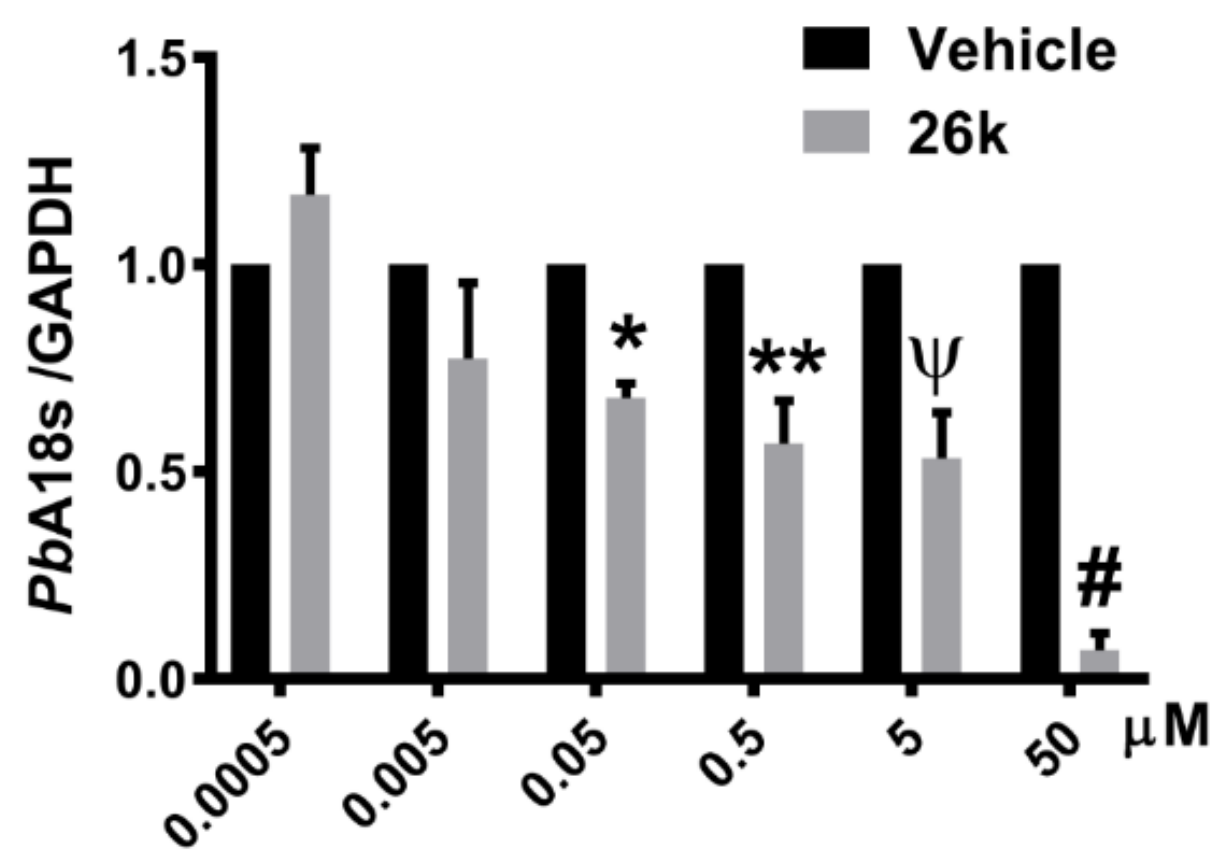

D

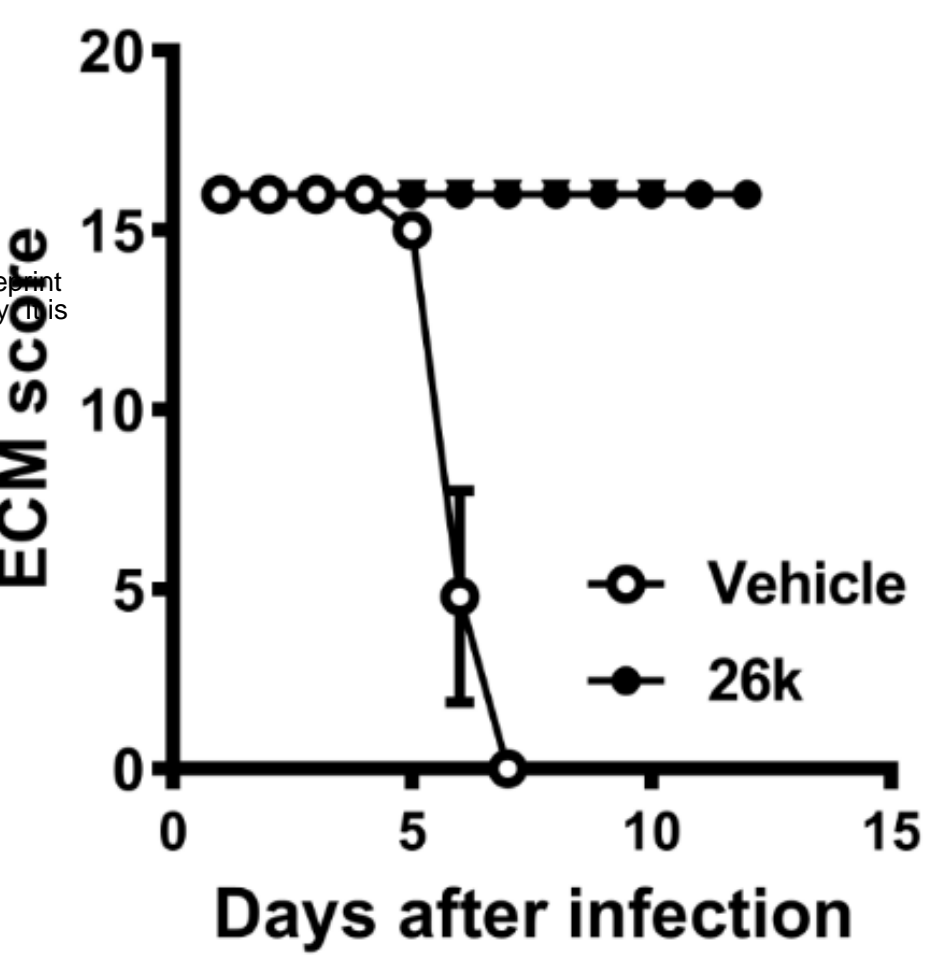

